\title{
Catalytic Reforming: Methodology and Process Development for a Constant Optimisation and Performance Enhancement
}

Priscilla Avenier, Delphine Bazer-Bachi, Frédéric Bazer-Bachi, Céline Chizallet, Fabrice Deleau, Fabrice Diehl, Julien Gornay, Éric Lemaire*, Virginie Moizan-Basle, Cécile Plais, Pascal Raybaud, Florence Richard and Sylvie Lacombe

\author{
IFP Energies nouvelles, Rond-point de l'échangeur de Solaize, BP 3, 69360 Solaize - France \\ e-mail: priscilla.avenier@ifpen.fr - delphine.bazer-bachi@ifpen.fr - frederic.bazer-bachi@ifpen.fr - celine.chizallet@ifpen.fr - \\ fabrice.deleau@ifpen.fr - fabrice.diehl@ifpen.fr - julien.gornay@ifpen.fr - eric.lemaire@ifpen.fr - virginie.moizan@ifpen.fr - \\ cecile.plais@ifpen.fr - pascal.raybaud@ifpen.fr - florence.richard@ifpen.fr - sylvie.lacombe@ifpen.fr \\ * Corresponding author
}

\begin{abstract}
Catalytic reforming process has been used to produce high octane gasoline since the 1940s. It would appear to be an old process that is well established and for which nothing new could be done. It is however not the case and constant improvements are proposed at IFP Energies nouvelles.

With a global R\&D approach using new concepts and forefront methodology, IFPEN is able to:

- propose a patented new reactor concept, increasing capacity;

- ensure efficiency and safety of mechanical design for reactor using modelization of the structure;

- develop new catalysts to increase process performance due to a high comprehension of catalytic mechanism by using, an experimental and innovative analytical approach $\left({ }^{119} \mathrm{Sn}\right.$ Mössbauer and $X$-ray absorption spectroscopies) and also a Density Functional Theory (DFT) calculations;

- have efficient, reliable and adapted pilots to validate catalyst performance.
\end{abstract}

Résumé - Le reformage catalytique : méthodologie et développement procédé pour une optimisation et une amélioration constante des performances — Le reformage catalytique est utilisé pour produire des essences à haut indice d'octane depuis les années 40 . Il pourrait apparaître comme un « vieux » procédé mature et pour lequel aucune innovation n'est possible. Ce n'est pourtant pas le cas, et des améliorations permanentes y sont apportées par IFP Energies nouvelles.

À l'aide d'une stratégie de recherche globale, IFPEN est en mesure de :

- proposer un nouveau concept de réacteur breveté augmentant la capacité ;

- assurer l'efficacité et la fiabilité des designs mécaniques des réacteurs via la modélisation fine des structures ;

- développer des nouveaux catalyseurs augmentant les performances du procédé grâce à une compréhension poussée des mécanismes, ceci par le couplage d'expérimentation et de techniques analytiques innovantes $\left({ }^{119} \mathrm{Sn}\right.$ Mössbauer et X-ray absorption spectroscopies) et aussi par modélisation moléculaire quantique ;

- proposer des évaluations fiables, précises et optimisées des catalyseurs sur une gamme d'unité pilote adaptée. 


\section{INTRODUCTION}

Catalytic reforming process has been used to produce high octane gasoline since the 1940s with fixed bed technology and initially with platinum catalysts only. Later catalysts with rhenium were introduced. In 1970, the first unit using a catalyst circulation was industrialized with radial reactor technology. At the same time catalysts using tin were employed for circulation technology.

So catalytic reforming might appear to be an old process that is well established and for which nothing new could be done. This is however not the case and constant improvements are proposed. To achieve these objectives, each part of the process, from the catalyst formulation to the study of the materials and mechanical constraints, are regularly examined. This is made possible thanks to the development of new methodologies to improve knowledge on catalyst mechanisms, or technology limitations.

Different works undertaken at IFPEN illustrating these developments will be presented in this article, concerning:

- development of a new technology for a radial reactor, and its hydrodynamic characterization;

- mechanical modeling associated to mechanical tests to improve reactor design;

- use of state-of-the-art analytical methods and Density Functional Theory (DFT) to improve catalyst structure and our understanding of catalytic mechanisms;

- development of complete pilots panel for catalyst testing.

\section{RADIAL REACTOR TECHNOLOGY IMPROVEMENT}

Radial moving bed technology is classically used for catalytic reforming. In this type of reactor, catalyst particles move downwards under the influence of gravity in a channel between two coaxial cylinders, while gaseous feed is injected radially across the bed, generally inwards.

Operation of such reactors can be affected by disturbances affecting the solid flow: cavitation at gas inlet and pinning (granular bed stops moving) at the gas outlet. The main consequence is a limitation for the total pressure drop in the granular bed. Those phenomena have been widely discussed in open literature [1-4].

Recently, a change in reactor technology has been proposed so as to simplify unit operation and, above all, increase reactor capacity [5]. As a consequence, reactor design rules must be reconsidered for this new technology. In particular, solid movement in this new type of reactor has to be studied, which means both an experimental characterization and Computational Fluid Dynamics (CFD) modeling.

\subsection{Experimental Characterization of Catalyst Pinning}

Radial catalytic bed reactors are in the form of a vertical cylindrical ring delimited, on the inner side (gas outlet) by

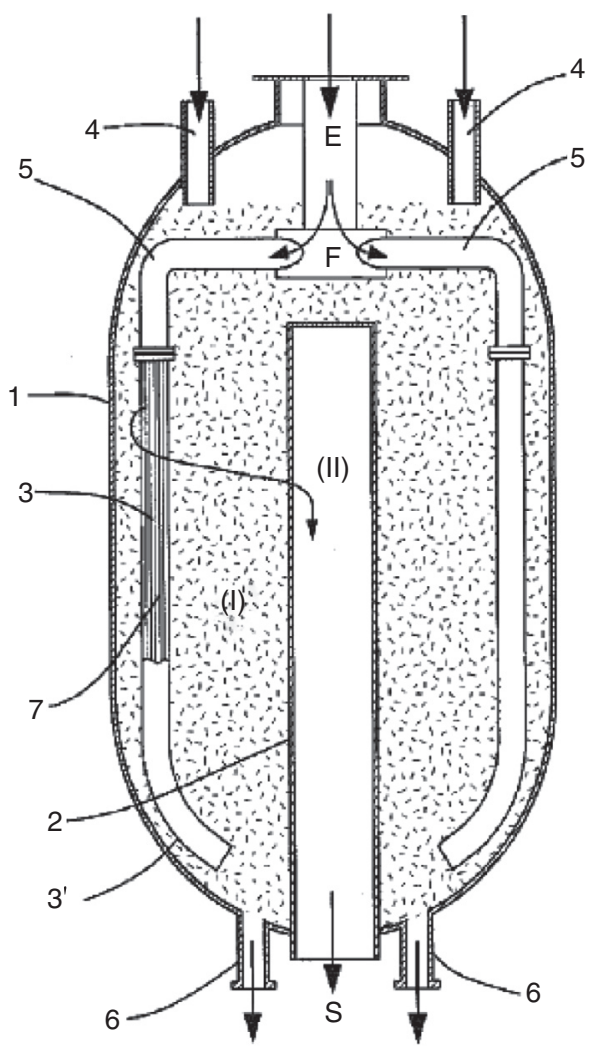

Figure 1

New technology for radial moving bed reactors: (1) reactor vessel, (2) inlet screen, (3) distribution tubes, (4) solid introduction and (6) withdrawal legs.

an inner screen retaining the catalyst and, on the outer side (gas inlet), either by a screen of the same type or by a device consisting of an assembly of screen elements (scallops).

Injection of gas feed with the new reactor technology is rethought: a plurality of distribution tubes are disposed inside the catalytic bed in the vicinity of the reactor wall (Fig. 1). In Figure 2, reduced velocities for solid flow are conventionally encountered A/ near the inner screen, i.e. gas outlet. With the new type of gas injection, one may also imagine disturbances $\mathrm{B} /$ between injection tubes and the reactor shell, and C/ between two injection tubes (Fig. 2).

A specific experimental apparatus (nine meter height) has been used with the objective of examining the three possible modes of disturbance affecting solid flow. Catalyst particles are first lifted to an elutriator device, at the top of the mockup, for the separation of fine material. Then, solid moves down at low velocity $\left(<10 \mathrm{~cm} \cdot \mathrm{s}^{-1}\right)$, first to a "pseudoreactor", then to the lift operation for the next circulating movement. Such a mock-up is obviously ideal in order to qualify mechanical strength of solid catalysts (attrition tests). 


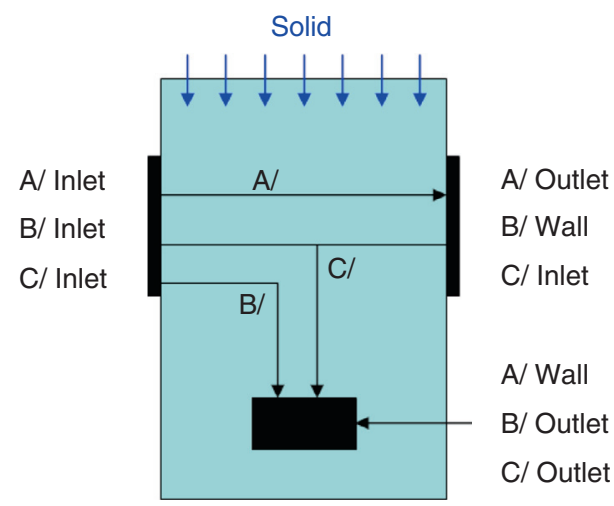

a)

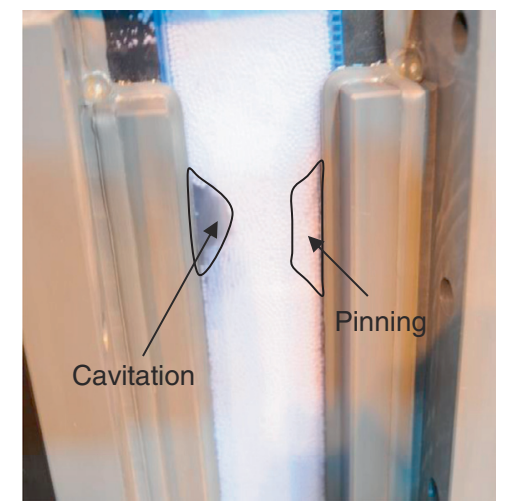

b)

Figure 2

a) Three possible configurations for the pseudo-reactor: position of gas inlets/outlets. b) Pseudo-reactor view.

The "pseudo-reactor" has a parallelepipedic section, with a small Plexiglas window (a width of 0.05 or $0.15 \mathrm{~m}$ for the catalytic bed) and associated pressure sensors. Three possible inlets/outlets for gas flow enable the test of the three potential modes of disturbance (Fig. 2).

Several tests are done by increasing/reducing the gas flow rate in the granular bed: possible disturbances for solid movement are visualized, pressure data being regularly collected.

For a classical configuration $\mathrm{A} /$, a pinning effect is observed above a certain pressure drop $\left(\Delta P_{\text {bed }} \sim 7 \mathrm{mBar}\right)$ for all bed widths, which is consistent with literature observations. Cavitation appears for gas inlet velocities higher than $1 \mathrm{~cm} \cdot \mathrm{s}^{-1}$.

For configurations $\mathrm{B} /$ and $\mathrm{C} /$, pinning is not observed, even for far larger pressure drops $\left(\Delta P_{\text {bed }}>30 \mathrm{mBar}\right)$. Thus, the change in reactor technology may only add disturbances for the solid flow by provoking more cavitation points near distribution tubes.

In relation to this cavitation phenomena, CFD modeling has been used to have an idea of the gas and solid velocities/streamlines in the new radial reactor at an industrial size.

\subsection{CFD Modeling}

CFD modeling of catalyst pinning has been conducted using the commercial code Barracuda $\mathrm{CPFD}^{\circledR}$. This code is a three-dimensional, incompressible, multiphase particle-in-cell method to simulate dense particle flows. This numerical technique solves the governing equations of the fluid phase using a continuum model and those of the particle phase using a Lagrangian model. This code is a form of discrete element method, where each particle has threedimensional forces from fluid drag, gravity, staticdynamic friction, particle collision and possibly other forces.
TABLE 1

Catalyst properties

\begin{tabular}{c|c|c|c|c}
\hline Shape & Diameter & $\begin{array}{c}\text { Bulk } \\
\text { density }\end{array}$ & $\begin{array}{c}\text { Apparent } \\
\text { density }\end{array}$ & $\begin{array}{c}\text { Solid flow } \\
\text { rate }\end{array}$ \\
\hline Spherical & $1.8 \mathrm{~mm}$ & $670 \mathrm{~kg} / \mathrm{m}^{3}$ & $1100 \mathrm{~kg} / \mathrm{m}^{3}$ & $800 \mathrm{~kg} / \mathrm{h}$ \\
\hline
\end{tabular}

TABLE 2

Gas properties

\begin{tabular}{c|c|c|c}
\hline Density & Molar mass & Viscosity & Gas flow rate \\
\hline $1.762 \mathrm{~kg} / \mathrm{m}^{3}$ & 22.7 g.mol & $0.019 \mathrm{cP}$ & $117543 \mathrm{~kg} / \mathrm{h}$ \\
\hline
\end{tabular}

As explained by Snider $(2001,2007)[6,7]$, the solution scheme allows for distributions of types, sizes, and density of particles. Particles are implicitly coupled to the fluid phase, and the fluid momentum and pressure equations are implicitly solved.

3D Navier-Stokes equations are used to describe the gas behaviour. Coupling between the gas and the catalyst is made through Wen and Yu drag law.

Gas and solids properties used for the simulations are recalled in Tables 1 and 2.

The gas reactant is equally injected through $N$ tubes but only the surface towards the external wall is used. The gas exits the simulation domain through the inner wall.

The solid is injected together with a small quantity of gas at the top of the reactor which then join the reactants injected through the internal tubes. The gas quickly homogenizes in the annular space without going up towards the shell (Fig. 3). No particles are entrained to the top.

The density of the solids is globally constant in the reactor, close to the maximum of compactness. Catalyst movement is downwards. 


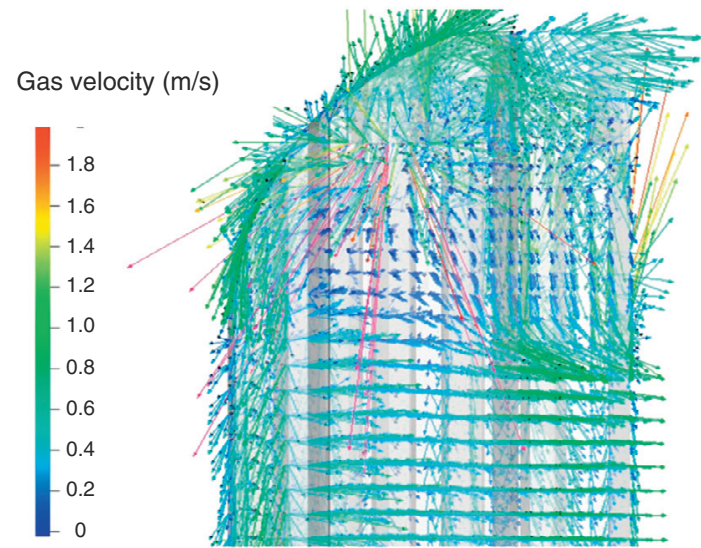

Figure 3

Gas velocity vectors at the top of the reactor.

The gas tends to accelerate locally, close to the reactor gas outlet (inner pipe) or between two tubes. On the other hand, in some areas located at the external part of the reactor, gas velocity is rather low. These zones are to be the smallest possible as potential dead zones. That implies that the tubes are located closer to the external reactor wall.

As a consequence, catalyst density is a little higher against the inner pipe but a little diluted at the gas injection (Fig. 4). Qualitatively, this result is consistent with the experimental ones where pinning is only predicted at the gas outlet and that a gas injection through a small surface can lead to local unpacking.

\subsection{Conclusions}

Catalytic reforming reactor technology has been recently improved so as to simplify unit operation and increase reactor capacity. This has led to several changes in the reactor design rules. Thanks to a dedicated cold mock-up and CFD modeling, design criteria have been proposed at the pilot scale and checked at the industrial scale.

As shown in this study, the change in reactor technology may only add disturbances for the solid flow by provoking more cavitation points near distribution tubes. Special care has to be given to design rules in that zone.

\section{GLOBAL BEHAVIOUR OF REFORMING REACTOR}

The object of this study is to understand the mechanical behaviour of a continuous catalytic reformer, in particular the tension or compression in the catalyst grains, in the center pipe and in the outer pipe. In this reactor, the bed of catalyst grains moves down continuously between two coaxial cylinders (the center pipe and the outer pipe) to regenerate decaying catalysts. There is a crossflow of gas from the outer cylinder to the inner cylinder.

\subsection{Reforming Reactor Model}

An axysimetric model was performed with a finite element method code (Abaqus $^{\mathrm{TM}}$ software). The catalyst grains are modelised by a homogeneous porous solid. Previous works on the mechanical behaviour of the catalyst bed have been done at IFPEN [8]. Its behaviour is similar to soils mechanics, Drucker-Prager plasticity model is used with the following relation:

$$
f(\underline{\underline{\sigma}})=\sqrt{J_{2}}-\alpha I_{1}-\beta=0
$$

where: $\underline{\sigma}$ is the stress tensor, $\alpha$ and $\beta$ are constants related to the friction and cohesion, $I_{1}$ the first stress invariant and $J_{2}$ the second invariant of the stress deviator tensor:

$$
I_{1}=\operatorname{tr} \underline{\underline{\sigma}} \text { and } J_{2}=\underline{\underline{S}}: \underline{\underline{S}}\left(\underline{\underline{S}}=\underline{\underline{\sigma}}-\frac{\operatorname{tr} \underline{\underline{\sigma}}}{3} \underline{\underline{1}}\right)
$$

More complicated laws exist [8], but are not used in this first approach.

The continuous catalytic reforming process is a dynamic process that we model by a series of static steps. There are three steps:

- the first step is the filling of the reactor: we apply the gravity $g$ and assume that there is no pressure;

- in the second step, the movement of the catalyst inside the reactor is introduced through a displacement of the nodes at the bottom of the mesh of the catalyst bed;

- the third step is the circulation, it consists of the injection of the radial gas inward. In this step, the velocity of gas injection $v$ is applied by increasing increments and the bottom of the catalyst bed moves down.

The model is a little reactor (Fig. 5) and it is chosen in order to understand the behaviour of the system. The characteristics of the model are a height of five meters and an annular space about $0.2 \mathrm{~m}$. The gas (air) is injected via a window (the height is $0.8 \mathrm{~m}$ ). The behaviour of the gas flow is described by Ergun's law. The head loss is taken as a function of the gas velocity:

$$
\frac{\Delta P}{L} g=\frac{150 \mu\left(1-n^{2}\right)}{d_{p}^{2} n^{3}} v+\frac{1.75(1-n) \gamma_{g}}{d_{p} n^{3}} v^{2}
$$

with $\Delta P$, the head loss through the distance $L, g$ the gravity, 150 and 1.75 experimental values, $n$ the porosity of the 


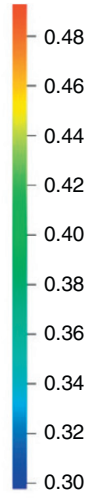

a)

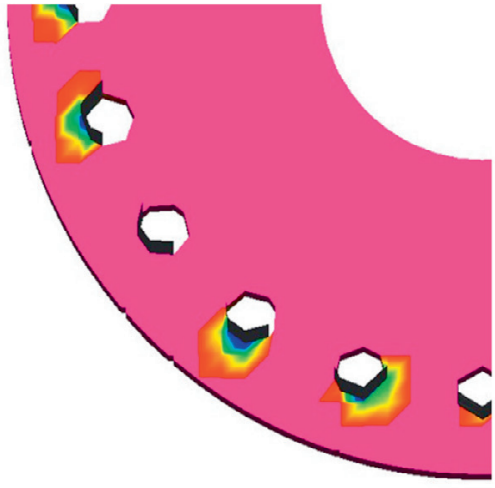

Figure 4

Solid density: a) zoom on the gas inlet and b) the center pipe.
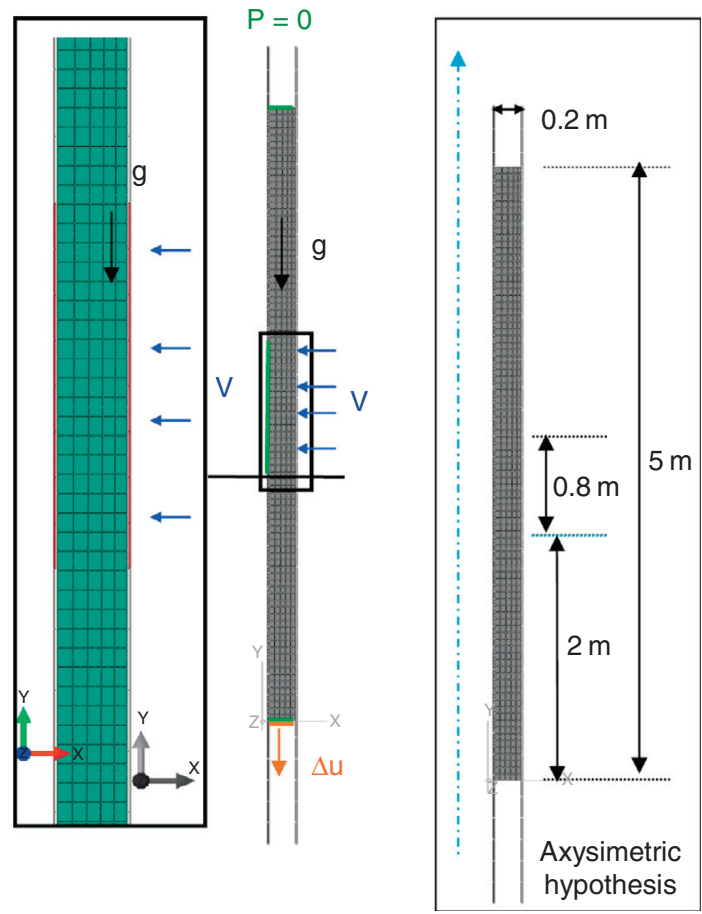

Figure 5

Design of reactor model.

catalyst bed, $d_{p}$ the average diameter of grains, $\gamma_{g}$ the weight density of gas and $\mu$ the dynamic viscosity of gas.

A contact law with friction is introduced in the model in order to reproduce catalyst / grid behaviour. The friction coefficient between Johnson grid and catalyst bed has been determined by tests at IFPEN in 1996.

\subsection{The Effort in Different Parts for Different Conditions}

The calculations performed, show that the weight of the catalyst bed is shared between the center pipe, the outer pipe and the catalyst bed. Each part depends on the friction coefficients (inside the catalyst bed and between the catalyst bed and Johnson grid) and the conditions (velocity of injection and pinning effects).

The catalyst weight transmitted by friction at the wall interface is shown in Figure 6 compared to Figure 7. The distribution force in the catalyst bed respects the Janssen's law shape [8]. The maximum effort is at the bottom of the outer pipe.

The injection of gas inward modifies the distribution of the efforts (Fig. 8): the efforts in center pipe increase and the efforts in the catalyst bed are not homogeneous in the radial direction.

Figure 9 shows that the values of the Janssen law in the catalyst bed are not exactly found with the Abaqus ${ }^{\mathrm{TM}}$ model. It is notified in other studies $[9,10]$.

In the catalyst bed, with the injection of gas, two different levels of the vertical effort appear: a lower value above the injection window and a greater value below the window (Fig. 8).

The increasing of the velocity of the injection gas modifies the distribution of the vertical effort between the different parts of the reactor (Fig. 10). The rate of the effort in the center pipe is maximum when the catalyst bed above the window is blocked (pinning effect). 


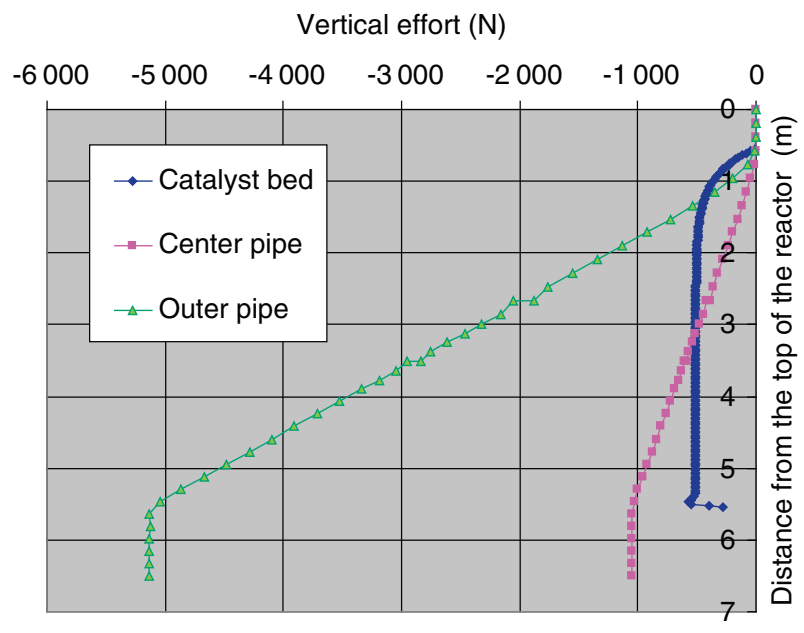

Figure 6

Effort in the reactor with friction between the catalyst bed and the Johnson grid.

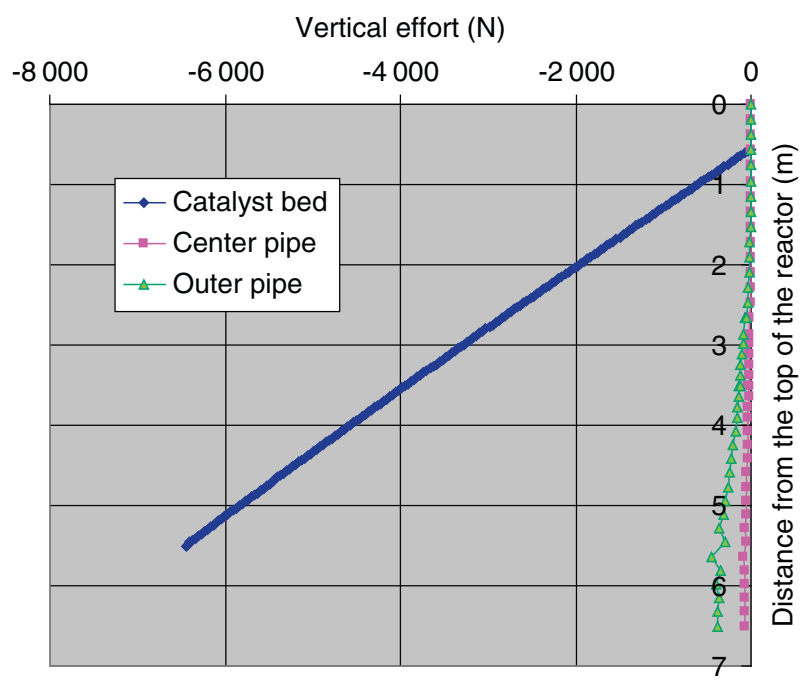

Figure 7

Effort in the reactor without friction between the catalyst bed and the Johnson grid.

The effort in the grids can be estimated with this type of study.

\subsection{Mechanical Structure Design Analysis, Analytical Approach}

The catalyst powder is contained between the center pipe and the external grid. The previous part of this paper highlights that the mechanical solicitation applied on the grid is

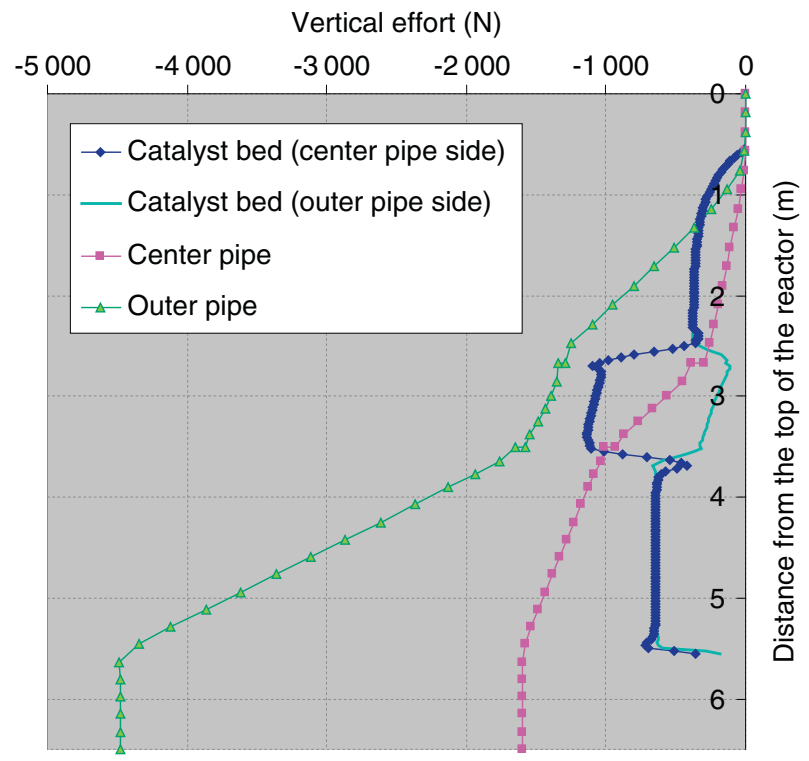

Figure 8

Effort in the reactor with friction between the catalyst bed and the Johnson grid, with injection gas.

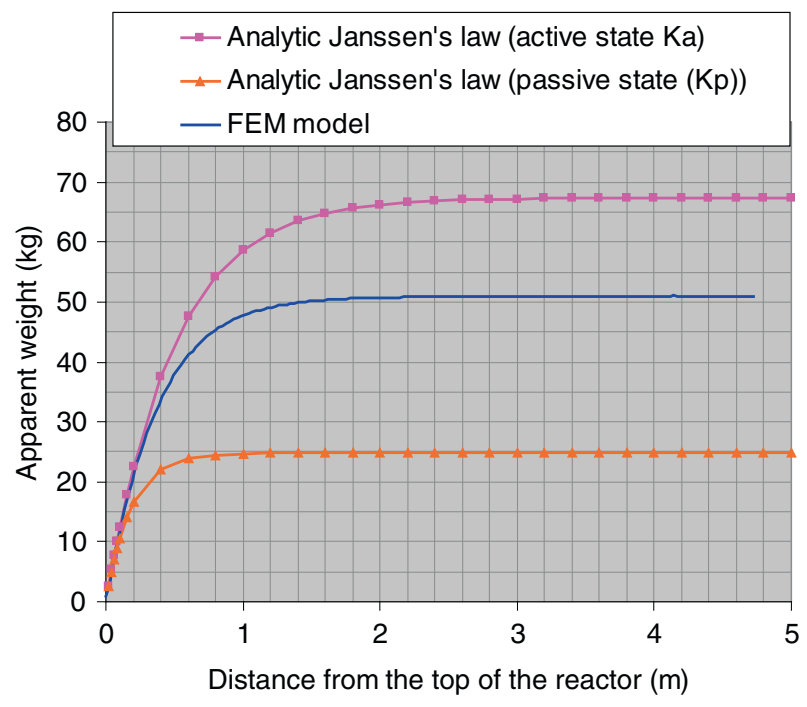

Figure 9

Different estimations of the apparent weight in the catalyst bed in function of the distance from the top of the reactor without injection gas.

produced by the friction between the catalyst and the grid. The grid must be designed to support the total weight of the catalyst to avoid its crash. This situation is considered when pinning occurs.

The mechanical design of this grid must be optimised as a function of this load. The structure is more and more slender; 


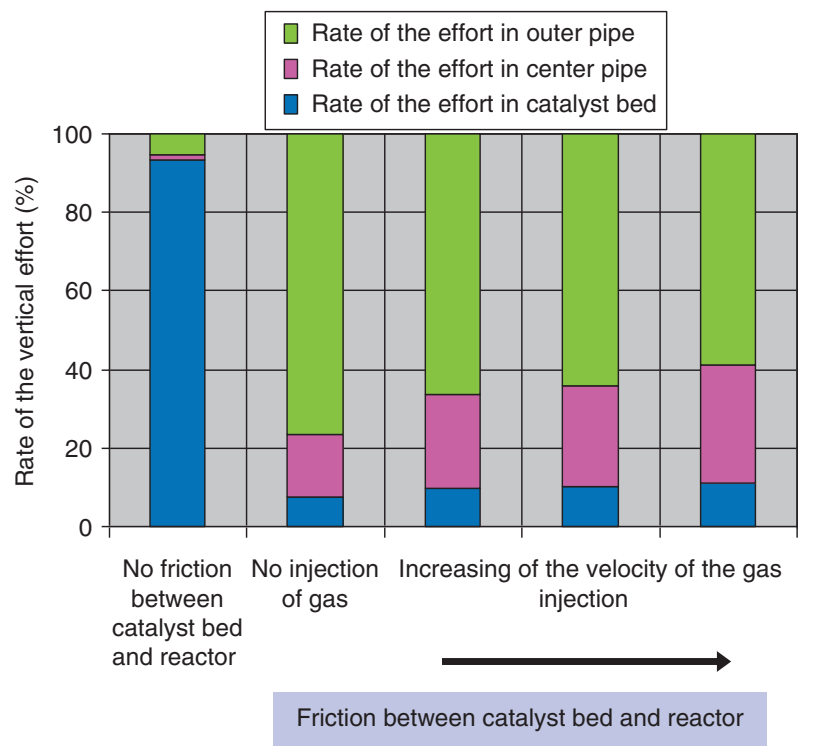

Figure 10

Evolution of the rate of the vertical effort in the different parts of the reactor as a function of the conditions.

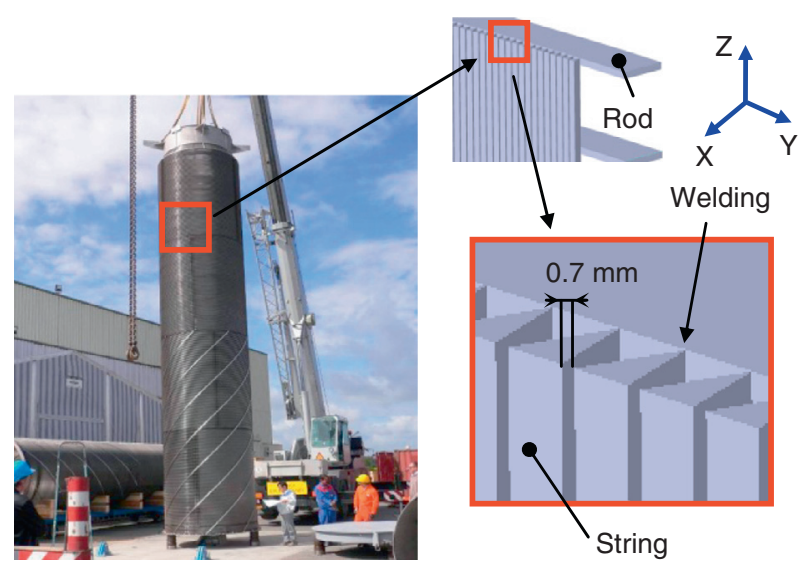

Figure 11

External grid, structure assembly. Orthotropic cylinder.

the structure height reaches $16 \mathrm{~m}$, the diameter $D_{m}$ is close to $4 \mathrm{~m}$ (Fig. 11). The design must be more precise, and sometimes enhanced to guarantee the system integrity. An analytical approach has been developed at IFPEN to evaluate the mechanical resistance of a cylinder filled with catalyst media. The cylinder is representative of the external grid built with vertical strings $\left(9.37 \mathrm{~mm}^{2}\right.$ section) and horizontal rods (rectangular section $25 \times 3 \mathrm{~mm}^{2}$ ). The distance between two rods is close to $25 \mathrm{~mm}$ and the slot between each string is $0.7 \mathrm{~mm}$. Each connection between the rod and the string is automatically welded in the manufacturing process.
The grid is considered as an orthotropic structure, the axial resistance is given by the string, the circumferential and radial resistance is given by the rod. The grid shear resistance is given by the rod and the string assembly: the welded connection. An equivalent section eq can be defined in the $X Y$ and $X Z$ plane and the ratio $\beta$ gives an estimation of the orthotropic level. The structure might be isotropic if $\beta$ is close to 1 :

$$
\beta=\frac{e_{e q X Z}}{e_{e q X Y}}
$$

whereas $\beta=1$, the grid cannot be considered as an isotropic material because its experimental shear modulus $G^{*}{ }_{12}$ reach $0.5 \mathrm{GPa}$ [11]. It is a hundred times smaller than an isotropic one $G_{12}$ Isotrope:

$$
G_{12 \text { Isotrope }}=\frac{E}{2 .(1+v)}
$$

$E$ is the Young's modulus (190 GPa) and $v$ the Poisson's ratio (0.3) of the AISI $321 \mathrm{H}$ material. Under operational conditions such as shown in the previous section, the grid is solicited by a vertical load which is a fraction of the catalyst weight. Paschero and Hyer (2009) [12] studied a similar structure in the aeronautic domain. This work was used and adapted to define a critical buckling stress $\sigma_{C R}$ of the grid structure:

$$
\sigma_{C R}=\frac{\eta \cdot E \cdot \sqrt{g_{12}}}{\sqrt{3 \cdot\left(1-v^{2}\right)}}
$$

where $g_{12}$ is the equivalent shear modulus and $\eta$ is a representative enhanced factor defined as follows:

$$
\eta=\frac{e_{e q X Y}}{D_{m} / 2}
$$

and

$$
g_{12}=\frac{G^{*}{ }_{12}}{G_{12 \text { Isotrope }}} \approx \frac{1}{100}
$$

The analysis of the critical stress permits the definition of a critical height. Under this height $h_{R}$, the structure is mechanically undersized and the structure can buckled:

$$
h_{R} \geq h \cdot\left(1-\frac{\sigma_{C R} \cdot e_{e q X Y}}{S .\left(F_{\text {Cata }} \cdot \%_{\text {Reprise }}+F_{\text {Steel }}\right)}\right)
$$

where: $h$ is the total height of the structure, $F_{\text {Cata }}$ is the weight of catalyst powder, $\%_{\text {Reprise }}$ is the percentage of catalyst weight support by the grid, as a consequence of the pinning effect, $F_{\text {Steel }}$ is the steel structure weight. 


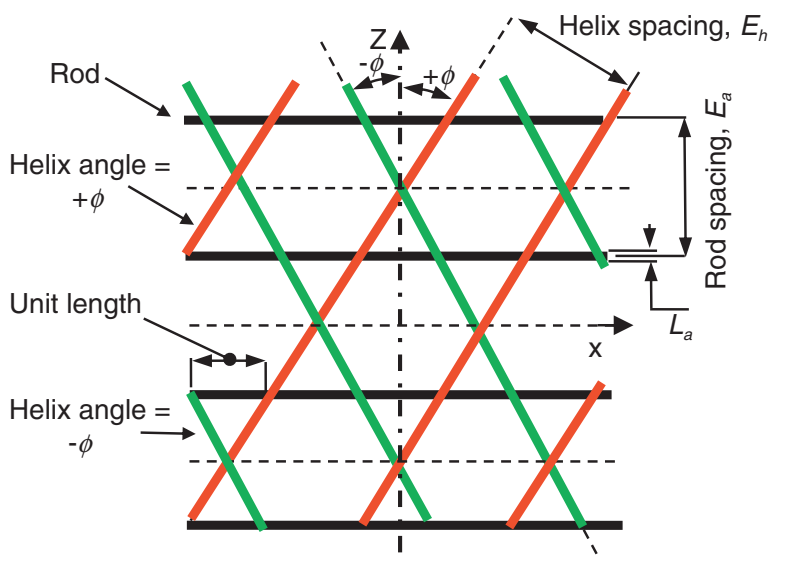

Figure 12

Double helix structure.

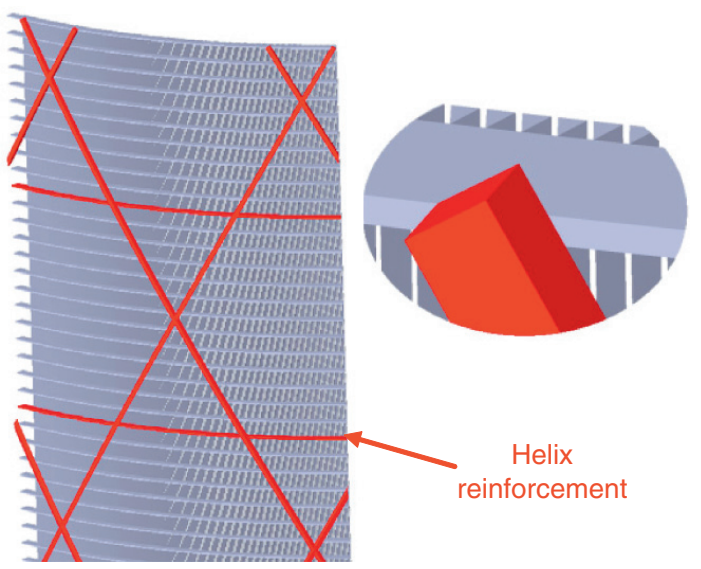

Figure 13

Reinforced solution.

\section{Helix Structure}

One solution to reinforce the grid is to install a double helix profile on the structure $[13,14]$ (one helix is installed on the grid in Fig. 11). A schematic view of this new structure is given in Figure 12.

The optimized helix angle $\phi$ is $30^{\circ}$ to support a vertical load. The work of Paschero and Hyer (2009) [12] defined the shear modulus as a function of $\phi$ :

$$
g_{12}=2 \cdot \sin \phi \cdot\left\lfloor\sin ^{2} \phi+\sqrt{\sin \phi+\sin ^{4} \phi}\right\rfloor
$$

The distance between the helix part and the rod must respect this relation:

$$
E_{h}=E_{a} \cdot 2 \cdot \sin \phi
$$

The critical stress for a vertical compression solicitation for the helix structure is:

$$
\sigma_{C R}=E . \eta . \delta . \psi
$$

with:

$$
\delta=\frac{L_{a}}{E_{a}}
$$

and

$$
\psi=\frac{\cos ^{2} \phi}{\sqrt{3 \cdot \sin \phi}}
$$

This analytical approach permits to specify a mechanical reinforcement to the initial structure.

\section{Structure Helix Reinforcement}

The helix reinforcement is taken into account in our design methodology. The design of the external grid combined the mechanical resistance of the initial orthotropic cylinder (gray part of Fig. 13) and the additional helix structure (red part of Fig. 13).

This system increases the buckling resistance versus a compression loading.

\subsection{Experimental Mechanical Characterization}

The previous analytical approach is based on material characteristics at $20^{\circ} \mathrm{C}$ like Young modulus $E(=190 \mathrm{GPa})$, elastic limit (=200 MPa), shear modulus $G(=0.5 \mathrm{GPa})$. These parameters have to be precise; one solution is an experimental investigation. The material properties were characterised before and after the mechanical assembly at ambient temperature. The string and the rod are more or less wiredrawn. The impact on the mechanical properties is important. The other and the most important advantage of this experimental study is the grid shear resistance characterization which is very difficult to estimate with numerical models.

\subsubsection{Tensile Characterization}

Many tensile tests were performed in the IFPEN Solaize laboratory (Fig. 14) in accordance with the EN ISO 6891-1 standard on the Instron Tensile equipment. This commercial apparatus allows the application of a maximal tensile effort equal to $250 \mathrm{kN}$. The tensile load, the global strain (between each curb) and a local strain (extensometer) are recorded at $10 \mathrm{~Hz}$ (Fig. 14). 


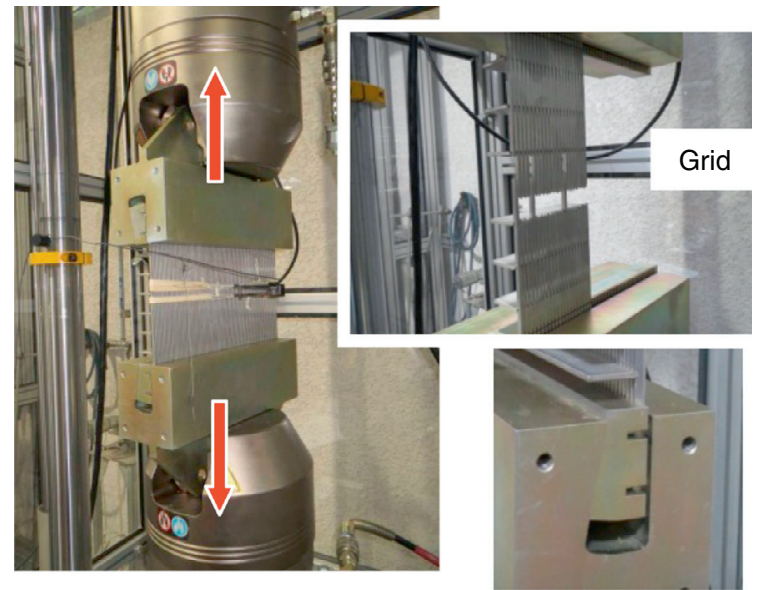

Figure 14

Experimental setup, Instron apparatus.

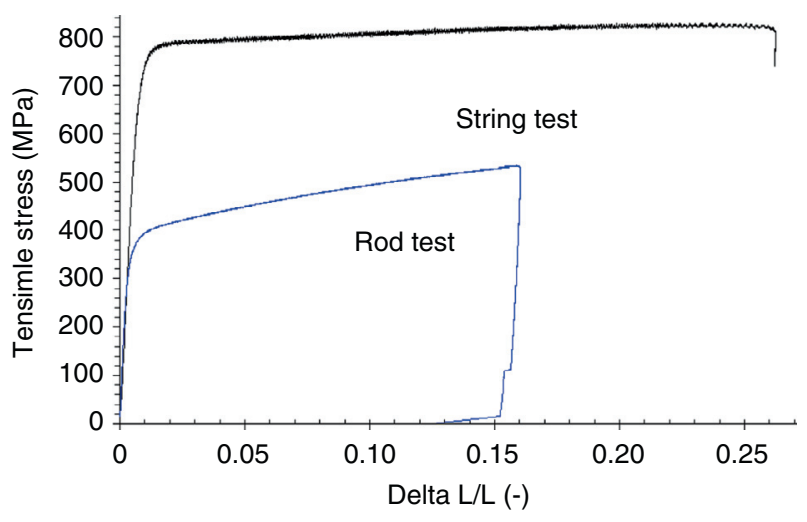

Figure 15

Tensile test on a string and rod (without welding).

A mechanical adaptation was designed in order to test a grid sample with this apparatus. Specific curbs were machined with the string footprints. The sample is composed of a maximum of 81 strings and the number of rods is limited by the space between the curbs $(150 \mathrm{~mm})$. The end of the tensile test is given by the sample braking or the maximal load system.

First of all, the string and the rod without a welded connection were characterised (Fig. 15). The string section is $9.37 \mathrm{~mm}^{2}$, the rod section is $75 \mathrm{~mm}^{2}$. The black curve is representative of the string and the blue one of the rod. The behaviour of these samples is characteristic of austenitic steel; the definition of the yield strength is difficult.

A clear difference is noted between the rod and the string, the yield strength at $0.2 \%$ of the strain is higher for the string

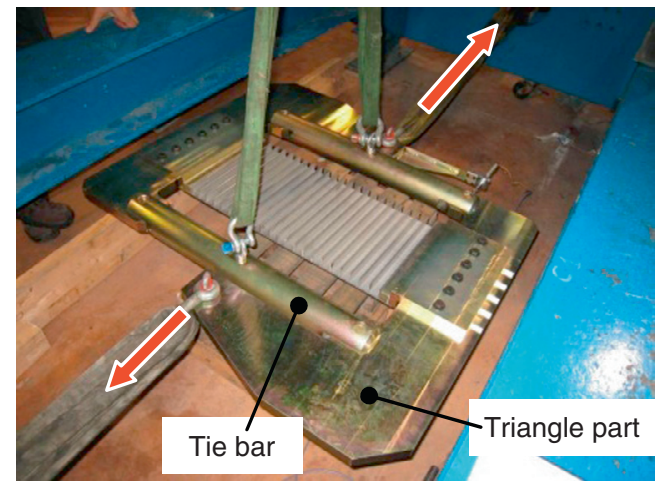

Figure 16

Experimental shear test setup.

$660 \mathrm{MPa}$ as the rod $360 \mathrm{MPa}\left(\right.$ at $20^{\circ} \mathrm{C}$ ). This can be explained in terms of the mechanical stress history of the string. Plastic deformation occurs in the string because the string was more wiredrawn than the rod. It is hardening so its mechanical properties increase.

Other tests were performed on the welded sample and permitted to conclude that the welded connection do not decrease the mechanical properties of the grid assembly. The welded connection is automatically made by an electric process. The thermal affected zone is much reduced. In conclusion, the grid mechanical properties in the string direction are given by the string and by the rod in the direction of the rod. The shear resistance is given by the string and welding characteristics. A special experimental setup was developed in our laboratory to characterize the shear resistance of the grid.

\subsubsection{Shear Resistance Analysis}

The shear resistance is an important data in the design methodology. A test bench was modified in order to only apply a shear stress on the grid sample (Fig. 16). The dimension of the grid is $600 \times 300 \mathrm{~mm}^{2}$ built with 23 rods and maximum of 81 strings. Clamps were installed at both ends between the end rod and the mechanical triangle part. Two tie-bars made the link between the two triangle parts to form a parallelogram. This assembly is solicited with a traction load and produces a shear stress on the grid.

The bench is instrumented with:

- a load sensor to measure the apply load,

- a displacement sensor to estimate the shear strain.

The experimental results in Figure 17 present the evolution of the strain versus the applied effort. The sample is plastically deformed. All tests are reproducible. 


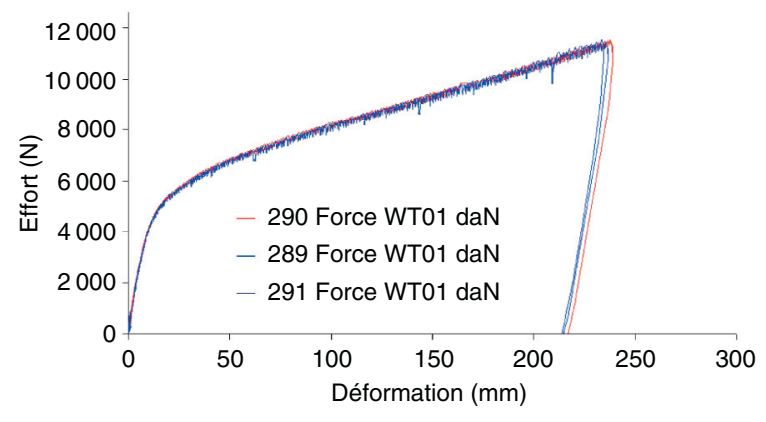

Figure 17

Shear test results made with 3 samples.

This experimental curve allows the determination of the shear stiffness $R_{c}$ of the sample, of the welding $\left(R_{s}\right)$ in the elastic domain:

\begin{tabular}{c|c|c}
\hline & $\mathrm{N} \cdot \mathrm{mm}^{-1}$ & $\mathrm{~N} \cdot \mathrm{rad}^{-1}$ \\
\hline Shear sample stiffness, $R_{c}$ & 90 & 50439 \\
\hline Shear welding stiffness, $R_{s}$ & 0.19 & 115 \\
\hline
\end{tabular}

The shear stress $\sigma$ is the product of the shear modulus $G$ with the shear strain and is equal to the ratio between the traction load with the shear section:

$$
\sigma=\gamma \cdot G \text { and } \sigma=\frac{F}{A}
$$

The shear stiffness $R_{c}$ is defined as below:

$$
R_{c}=\frac{F}{\gamma} \text { and } R_{c}=N_{f i l} \cdot R_{f i l}
$$

The shear stiffness $R_{c}$ is the product between the number $N_{f i l}$ and the string shear stiffness $R_{f i l}$. An important hypothesis is made that the shear resistance in the elastic domain is given by the string and not the welding (considered very stiff compared to the string). The shear modulus can be written as:

$$
G=\frac{F}{\gamma \cdot A}=\frac{R_{c}}{A}
$$

where $A$ is shear section which is proportional to the number $N_{f i l}$ and the section $S_{f i l}$ of string:

$$
A=S_{f i l} \cdot N_{f i l}
$$

The final formulation of the shear modulus is:

$$
G=\frac{R_{f i l}}{S_{f i l}}
$$

This approach estimates the shear modulus $G$ to be equal to $0.3 \mathrm{GPa}$. The shear resistance of the system is very low compared to an isotropic material. It is the weak point of the structure.

Different reinforced solutions have been tested with the same experimental setup and permit to increase the shear modulus to $1.08 \mathrm{GPa}$. A shear modulus $G=0.3$ is considered in our mechanical design. Current research efforts primarily focus on this theme to improve the grid design to make it more reliable, to understand the precise mechanical behaviour of the catalyst media [8] and the solicitation, to propose solutions to strengthen the mechanical structure.

\section{ANALYSIS AND DFT APPROACH FOR BETTER UNDERSTANDING OF CATALYST STRUCTURE AND CATALYTIC MECHANISMS}

The first naphtha reforming catalyst was introduced in 1949 and was composed of chlorinated alumina supported hyperdispersed platinum particles. Later, process performance has benefited from the introduction of bimetallic catalysts, Pt-Re for the fixed bed processes in the 70's and Pt-Sn for the continuous processes in the 80's [15]. Bimetallic systems allowed to enhance the liquid yield and the catalyst stability by decreasing coke formation, with specific reaction conditions and process technology for each system. Research efforts have then focused on improving preparation methods, support shaping, platinum phase and the introduction of promoters.

As market continuously requests enhanced performances, the addition of a second promoter to the bimetallic systems has recently received close attention. These multimetallic systems increase the complexity of catalysts by introducing a larger diversity of sites to an initial system that has not yet been fully understood. Identification of these new sites is of major interest to understand their role on the catalytic mechanism and to allow the development of new catalyst generations. For this purpose, dedicated characterization techniques and DFT calculations have been applied to reforming catalysts.

\subsection{Experimental Approach: ${ }^{119}$ Sn Mössbaver and X-Ray Absorption Spectroscopies}

We illustrate hereafter an example of the contribution of ${ }^{119} \mathrm{Sn}$ Mössbauer and X-ray absorption spectroscopies to the description of multimetallic Pt-Sn-In catalytic systems, in which the promoters can be introduced either by wet impregnation or by co-precipitation with aluminium precursors when preparing the support. In these catalysts, the way the promoters are introduced is a key to tune their localization and interaction with platinum.

The Mössbauer effect, discovered by Rudolf Mössbauer in 1958, consists of the recoilless emission of gamma ray photons from radioactive nuclei, and the selective resonant 


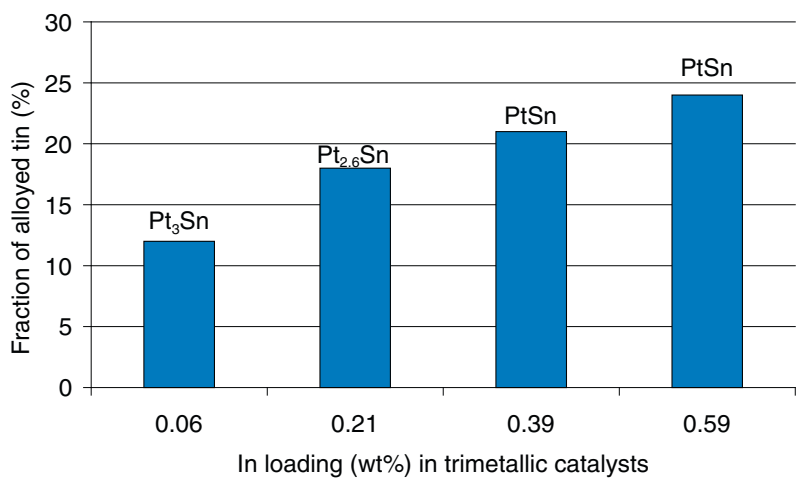

Figure 18

Composition of $\mathrm{Pt}_{x} \mathrm{Sn}$ alloys and the fraction of total tin alloyed with platinum in the co precipitated trimetallic catalysts as a function of their In loading.

re-absorption of these photons by other nearby nuclei. The method is sensitive to structure differences between emitting and absorbing nuclei. Mössbauer spectroscopy uses this phenomenon to explore the nuclear and atomic structures of materials. This technique is well applied in the characterization of heterogeneous catalysts, and among them PtSn-based catalysts [16-18]. It permits the identification of the various $\mathrm{Sn}$ species [19-21] and is well suited for a precise determination of their oxidation state and coordination pattern, the covalence degree of the chemical bonds and the relative fraction for each coexisting Sn species. The phases are described by their hyperfine parameters, i.e. the isomer shift $\delta\left(\mathrm{mm} . \mathrm{s}^{-1}\right)$ and the quadripole splitting $\Delta\left(\mathrm{mm} . \mathrm{s}^{-1}\right)$.

Recently, Mössbauer spectroscopy allowed to evidence the formation of $\mathrm{Pt}_{x} \mathrm{Sn}$ alloys when adding In to $\mathrm{PtSn}$ systems to form trimetallic reforming $\mathrm{Pt} / \mathrm{Al}_{2} \mathrm{O}_{3} \mathrm{SnIn}-\mathrm{Cl}$ catalysts, where both In and $\mathrm{Sn}$ were introduced by co-precipitation with aluminium precursors [17]. This alloy was absent from the corresponding bimetallic PtSn systems and is inherent to the presence of indium. The nature and the amount of alloy is moreover directly related to indium loading in the catalyst as shown in Figure 18. Increasing indium loading not only increases the fraction of tin alloyed to platinum but also enhances the amount of tin in the alloy, starting from a $\mathrm{Pt}_{3} \mathrm{Sn}$ alloy at low indium loading $(0.06 \mathrm{wt} \%)$ to a Sn rich PtSn alloy at higher loadings (0.4 and $0.6 \mathrm{wt} \% \mathrm{In})$. This relative amount of $\mathrm{Pt}$ and $\mathrm{Sn}$ in the alloys was directly deduced from the isomer shifts in the ${ }^{119} \mathrm{Sn}$ Mössbauer spectra: phases with lower isomer shifts are richer in $\mathrm{Pt}$ and those with higher isomer shifts are richer in Sn [17].

The introduction of indium and tin by impregnation on alumina to prepare $\mathrm{PtSnIn} / \mathrm{Al}_{2} \mathrm{O}_{3}-\mathrm{Cl}$ type catalysts led to completely different observations. ${ }^{119} \mathrm{Sn}$ Mössbauer

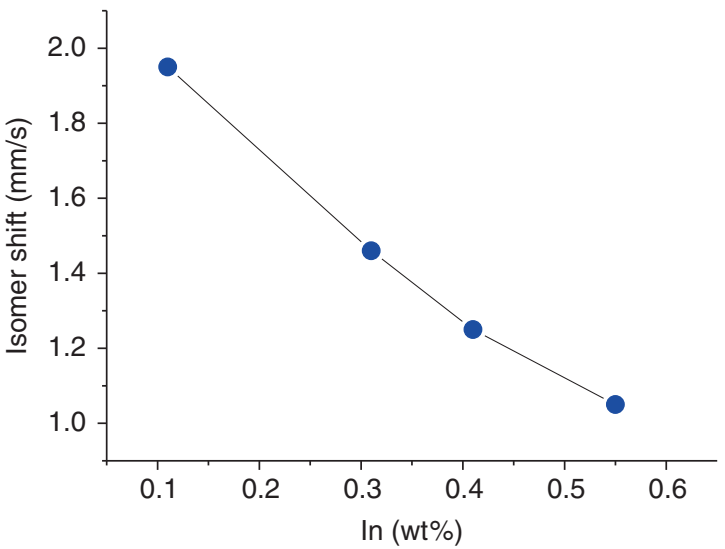

Figure 19

Evolution of the observed isomer shift value $\delta\left(\mathrm{mm} \cdot \mathrm{s}^{-1}\right)$ of the $\mathrm{Pt}_{x} \mathrm{Sn}(\mathrm{O})$ phase in impregnated trimetallic $\mathrm{PtSnIn} / \mathrm{Al}_{2} \mathrm{O}_{3}-\mathrm{Cl}$ catalysts as a function of In content.

spectroscopy reveals the presence of a Pt-Sn intermetallic species, labelled $\mathrm{Pt}_{x} \mathrm{Sn}(\mathrm{O})$ species, as it was previously observed for other bimetallic PtSn catalyst [21], but no alloy is evidenced. Pt and Sn relative atomic concentrations in these $\mathrm{Pt}_{x} \mathrm{Sn}(\mathrm{O})$ phases were estimated from the isomer shifts, assuming the same trend as the one applied for $\mathrm{Pt}_{x} \mathrm{Sn}$ alloys, i.e. the species with the higher isomer shifts being the richer in Sn. As In loading increases in the catalysts, isomer shift of the $\mathrm{Pt}_{x} \mathrm{Sn}(\mathrm{O})$ phase decreases, i.e. less $\mathrm{Sn}$ is engaged in this phase (Fig. 19). Tin and indium are competing for the proximity to platinum.

As ${ }^{119} \mathrm{Sn}$ Mössbauer spectroscopy was used to shed light on the Pt-Sn interactions, X-ray Absorption Near Edge Structure (XANES) was used to describe Pt-In ones. On the XANES spectra of the reduced catalysts at $\mathrm{Pt}_{3}$ edge (Fig. 20), the whiteline position $\left(E_{0}\right)$ and intensity reveal the interactions between elements [22].

In impregnation on $\mathrm{Pt} / \mathrm{Al}_{2} \mathrm{O}_{3}-\mathrm{Cl}$ induces significant modifications in the whiteline structure, intensity and position. Compared to $\mathrm{Pt} / \mathrm{Al}_{2} \mathrm{O}_{3}-\mathrm{Cl}$, $\mathrm{PtIn} / \mathrm{Al}_{2} \mathrm{O}_{3}-\mathrm{Cl}$ has a broader and less intense whiteline which is shifted by $1.80 \mathrm{eV}$ (the whiteline positions $E_{0}$ and the shifts $\Delta E_{0}(\mathrm{eV})$ for catalysts relative to reduced $\mathrm{Pt} / \mathrm{Al}_{2} \mathrm{O}_{3}-\mathrm{Cl}$ are listed in the table included in Fig. 20). This indicates a change in the electronic structure of Pt related to the presence of high amounts of Pt-In structures, probably in the form of alloys.

The XANES spectra of the trimetallic catalysts are clearly more similar to the spectrum of the bimetallic catalyst with In than with Sn. Compared to bimetallic $\mathrm{PtIn} / \mathrm{Al}_{2} \mathrm{O}_{3}-\mathrm{Cl}$, trimetallic catalysts with 0.31 and $0.41 \mathrm{wt} \%$ In present whiteline shifts of comparable orders which shows a modification of Pt structure due to In presence. As the In loading increases 


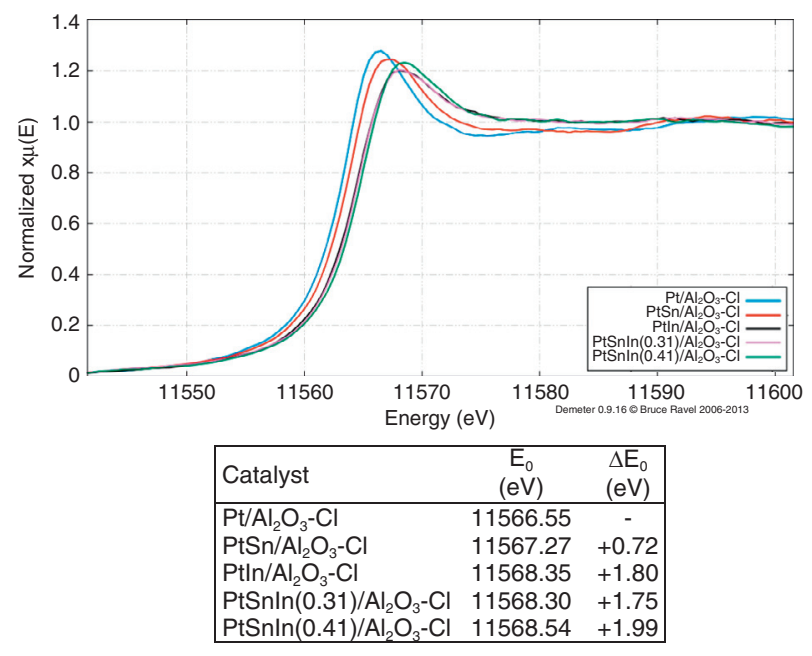

Figure 20

XANES spectra at the $\mathrm{Pt} \mathrm{L}_{3}$ edge for reduced monometallic $\mathrm{Pt} / \mathrm{Al}_{2} \mathrm{O}_{3}-\mathrm{Cl}$, bimetallic $\mathrm{PtSn} / \mathrm{Al}_{2} \mathrm{O}_{3}-\mathrm{Cl}$ and trimetallic $\mathrm{PtSnIn} /$ $\mathrm{Al}_{2} \mathrm{O}_{3}-\mathrm{Cl}$ catalysts (with variable In loadings) obtained by successive impregnations $E_{0}$ values $(\mathrm{eV})$ of reduced catalysts and shifts in $E_{0}\left(\Delta E_{0}\right)$ relative to reduced $\left(500^{\circ} \mathrm{C}, 2 \mathrm{~h}, \mathrm{H}_{2}\right)$ $\mathrm{Pt} / \mathrm{Al}_{2} \mathrm{O}_{3}-\mathrm{Cl}$.

in the trimetallic catalyst, more Pt-In intermetallic phases are formed. This observation fits with ${ }^{119} \mathrm{Sn}$ Mössbauer results showing decreasing $\mathrm{Sn}$ concentration in the formed $\mathrm{Pt}_{x} \mathrm{Sn}(\mathrm{O})$ phases as the In loading increased, in accordance with a substitution of Sn by In.

It results from these two studies that the association of tin with platinum is strongly influenced by the way indium is introduced and by its loading on the catalyst. Introducing indium by co-precipitation leads to enhanced Pt-Sn proximity, with the formation of a PtSn alloy at high In loadings (around $0.6 \mathrm{wt} \%$ ). In introduction by impregnation leads to a competition between $\mathrm{In}^{0}$ and $\mathrm{Sn}^{0}$ in a non-alloyed PtSnIn intermetallic structure (Fig. 21).

It was possible to further enhance the $\mathrm{Sn}^{0} / \mathrm{Pt}$ rate that is a lever to improve catalyst selectivity, by the use of surface organostannic chemistry to allow a selective Sn deposition on Pt particles. Even with this controlled deposition, the effect of indium localization, either on the support by impregnation or into the support by co-precipitation with aluminium precursor, leads to a maximization of PtSn alloy formation when indium is introduced in the support, with a $35 \%$ fraction of tin alloyed with platinum for a $\mathrm{SnPt} / \mathrm{Al}_{2} \mathrm{O}_{3} \mathrm{In}-\mathrm{Cl}$ catalyst. Finally, the combination of DFT calculations with the ${ }^{119} \mathrm{Sn}$ Mössbauer and X-ray absorption spectroscopies observations allowed to rationalize this particular behaviour [23] and to reveal the key role of $\mathrm{In}^{3+}$ species on the formation of $\mathrm{Pt}_{x} \mathrm{Sn}$ alloys, by stabilizing $\mathrm{Pt}_{x} \mathrm{Sn}$ clusters thanks to $\mathrm{Sn}^{0}-\mathrm{In}^{3+}$ bond formation.

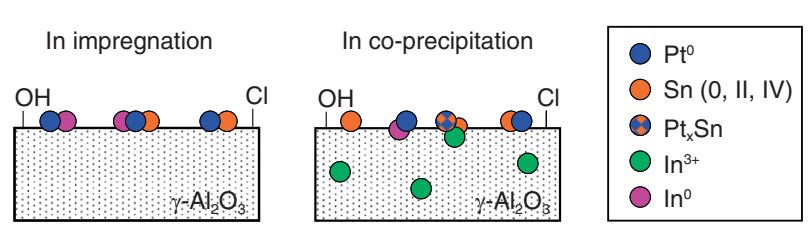

Figure 21

General model of SnPtIn based catalysts, prepared by impregnation of Pt and deposition of Sn by surface organometallic chemistry, the In promoter being introduced either by support impregnation or by co-precipitation during support preparation. Although not explicitly mentioned, $\mathrm{Pt}_{x} \mathrm{In}_{y}$ and $\mathrm{Sn}_{x} \mathrm{In}_{y}$ alloys cannot be excluded.

\subsection{DFT Calculations: Models of Reforming Catalysts}

As can be seen from the state-of-the-art characterization works of reforming catalysts, the very small size of the metallic particles and poorly defined nature of the support make it hard to get unambiguous representations of the catalyst at the molecular scale. To get a deeper insight in the structure and behaviour of active sites in catalytic reforming, we performed DFT calculations coupled to a thermodynamic model. The complexity of the industrial multi-metallic catalyst was taken into account by a step-by-step approach, dealing first with monometallic, then multimetallic systems.

As a first step, relevant models of monometallic platinum particles supported on $\gamma$-alumina $\left(\gamma-\mathrm{Al}_{2} \mathrm{O}_{3}\right)$ were obtained $[24,25]$, based on previous works providing surface models of $\gamma-\mathrm{Al}_{2} \mathrm{O}_{3}$ on one hand [26-29], and models of metallic nonsupported clusters on the other hand [30]. Mainly, two crystallographic orientations of the alumina framework [29] were considered: the (100) surface is generally dehydroxylated in catalytic reforming conditions, whereas the (110) is still hydroxylated [26, 27], possibly chlorinated [28].

With the aim of providing relevant models for reforming catalysts, platinum clusters containing 13 atoms were considered as being representative of highly dispersed platinum catalysts with particle size close to $1 \mathrm{~nm}$. Smaller particles (from 1 to 5 atoms) were also considered. For isolated clusters, the following general rule holds: the bigger the size, the more stable the cluster (Fig. 22a). By contrast, DFT calculations performed on supported $\mathrm{Pt}_{1-13}$ clusters demonstrated the significant impact of the rearrangement and migration of surface species (protons, hydroxyls, chlorine) to stabilize the smallest Pt clusters. This is mainly explained by the anchoring of the clusters to the surface via Pt-O and Pt-Al bonds. Including migration, Pt clusters are more stable on the hydrated and chlorinated (110) surfaces than on the dehydrated (100) surface. On the chlorinated (110) surfaces, $\mathrm{Pt}_{3}$ corresponds to a local energy minimum (Fig. 22a), even lower than $\mathrm{Pt}_{13}$. This stability of $\mathrm{Pt}_{3}$ would explain an 

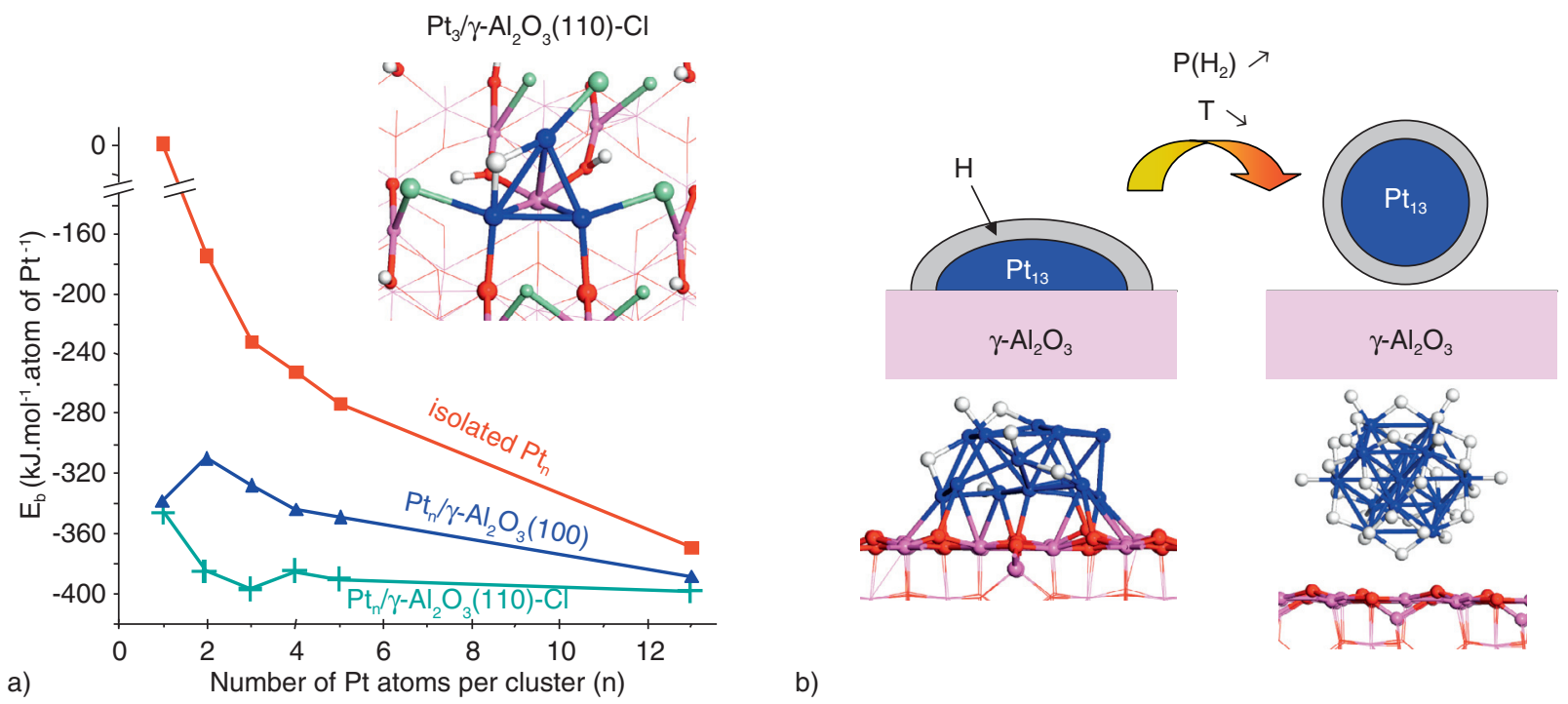

b)
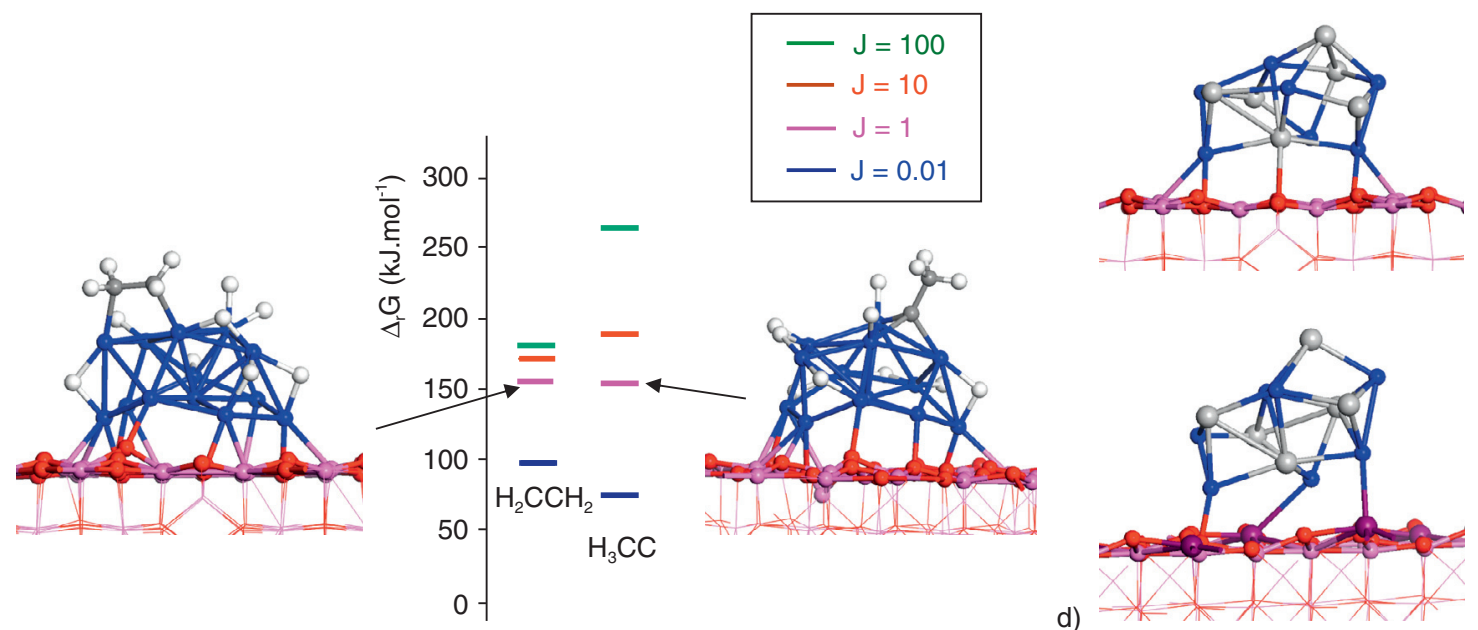

d)

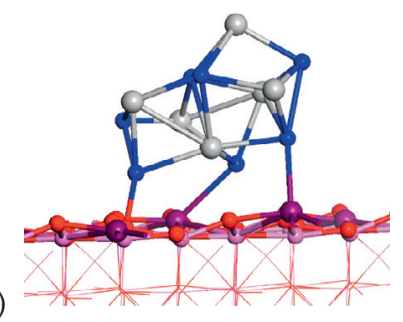

$\mathrm{Pt}$

Q Sn

$\mathrm{Al}$

In

0

$\mathrm{Cl} \odot \mathrm{C} \quad \mathrm{OH}$

Figure 22

DFT results of the simulation of model reforming catalysts: a) calculated binding energy (including Pt-Pt cohesion and metal-support interaction) of $\mathrm{Pt}_{n}$ clusters, isolated or supported on $\gamma-\mathrm{Al}_{2} \mathrm{O}_{3}$ [25]; the most stable $\mathrm{Pt}_{3}$ cluster supported on chlorinated $\gamma-\mathrm{Al}_{2} \mathrm{O}_{3}$ is shown in inset; b) effect of hydrogen pressure on the morphology change of supported $\mathrm{Pt}_{13}$ [33]; c) relative stabilities of adsorbed ethylene $\left(\mathrm{H}_{2} \mathrm{CCH}_{2}\right)$ and ethylidyne $\left(\mathrm{CCH}_{3}\right)$ on $\mathrm{Pt}_{13}$ supported cluster at various $J=P\left(\mathrm{H}_{2}\right) / P\left(\mathrm{C}_{2} \mathrm{H}_{6}\right)$ values; insets: illustrations of adsorbed ethylene and ethylidyne at $J=1$ [42]; d) models of supported PtSn catalysts, without (top) or with (bottom) indium incorporated in the support [23].

increase of the activation barrier to form larger clusters, thus limiting sintering, thanks to chlorine [31, 32].

In a second step, the reactivity of hydrogen towards platinum was investigated on the $\mathrm{Pt}_{13} / \gamma-\mathrm{Al}_{2} \mathrm{O}_{3}(100)$ system [33]. On this surface, in the absence of hydrogen, the $\mathrm{Pt}_{13}$ cluster preferentially lies in the "BiPlanar" (BP) morphology (Fig. 22b, left) and maximizes the metal-support interaction through Pt-O and Pt-Al bonds. The calculations show that this structure presents a strong affinity towards hydrogen.
The increase of hydrogen coverage may reach a $\mathrm{H} / \mathrm{Pt}$ atomic ratio greater than 1.4 , which induces a cluster reconstruction from the BP to a cuboctahedral (CUB) morphology (Fig. 22b, right) as shown by molecular dynamics. The $\mathrm{H} / \mathrm{Pt}$ ratio exceeding 1 - often observed in experimental analysis conditions $[34,35]$ - is rationalized by this reconstruction process. The electrostatic charge analysis reveals that a hydride phase is obtained for the CUB structure, with the partial loss of the metallic nature of 
$\mathrm{Pt}_{13}$. In contrast, for reaction conditions such as catalytic reforming $\left(T \sim 800 \mathrm{~K}\right.$ and $P\left(\mathrm{H}_{2}\right) \sim 10$ bar), the particle remains $\mathrm{BP}$ with moderate $\mathrm{H} / \mathrm{Pt}$ ratio (0.5-1). The electronic analysis also shows that it keeps its metallic character. These results account for numerous experimental data (TemperatureProgrammed Desorption, TPD; X-ray Absorption Spectroscopy, XAS; High-Resolution Transmission Electron Microscopy, HRTEM, etc.) [22, 36-40]. They were recently completed thanks to additional calculations of hydrogen interaction with $\mathrm{Pt}_{13} / \gamma-\mathrm{Al}_{2} \mathrm{O}_{3}(110)$ systems, and compared to HERFD-XANES (High Energy Resolution Fluorescence Detection - X-ray Absorption Near Edge Structure), showing that the hydrogen coverage is likely systematically overestimated by DFT, even if the trends are confirmed [41].

Then, to better describe and understand the impact of hydrogen in the catalytic reactions, we performed a DFT study of the stability of $\mathrm{C}_{x} \mathrm{H}_{y}(x=1$ or 2 and $0 \leq y \leq 5)$ intermediates likely formed upon activation of ethane considered as a model molecule for probing $\mathrm{C}-\mathrm{C}$ and $\mathrm{C}-\mathrm{H}$ bond scission on supported $\mathrm{Pt}_{13}$ clusters at variable hydrogen coverage [42]. Symmetric (one $\mathrm{H}$ removed on each $\mathrm{C}$ atom) and dissymmetric (H removed first on the same $\mathrm{C}$ atom) dehydrogenation elementary steps were compared, as well as $\mathrm{C}-\mathrm{C}$ bond breaking with $\mathrm{CH}_{4}$ release. Calculated relative Gibbs free energy profiles for the transformation of ethane allowed the quantification of the relative stability of $\mathrm{C}_{x} \mathrm{H}_{y}$ species relevant for dehydrogenation and hydrogenolysis pathways as a function of reaction conditions. The impact of the $J$ ratio of partial pressure of hydrogen over partial pressure of ethane $\left(J=P\left(\mathrm{H}_{2}\right) / P(\right.$ ethane $)=0.01,1,10$ and 100$)$ was studied (Fig. 22c). According to the DFT and thermodynamic calculations, intermediate $J$ values between 1 and 10 correspond to the optimal balance between the two dehydrogenation pathways, the $\mathrm{C}-\mathrm{C}$ bond scission leading to coke precursors or surface carbide, and the formation of $\mathrm{CH}_{4}$. Simultaneously, ethylidyne $\left(\mathrm{CCH}_{3}\right.$ in Fig. 22c), considered as a dead end intermediate, is thermodynamically less stable with respect to ethylene as soon as $J$ becomes greater than 1 . Within a similar range of $J$, hydrogenolysis reaction is also expected to be promoted due to the simultaneous stabilization of monocarbonaceous species on the platinum clusters with high hydrogen coverage. As a consequence, our DFT study identified and quantified the interval of process conditions to be used for favouring moderate dehydrogenation of ethane into ethylene. It also gives a way to identify quantitatively the thermodynamic optima in hydrogen pressure for either dehydrogenation or hydrogenolysis and avoiding coke formation as targeted in process conditions [43-46].

The next step towards a more accurate modeling of the real reforming catalyst is to consider the multimetallic nature of the catalysts. We recently started to undertake this by focusing on PtSn formulations, eventually with Indium as co-doping element present in the support as $\mathrm{In}^{3+}$ state (Fig. 22d), to shed new light on the experimental results explained in the previous section [23]. While tin is shown to decrease the metal-support interaction as compared to pure platinum, indium helps to compensate part of the interaction loss resulting in a stabilization of the bimetallic PtSn nano-cluster.

DFT calculations thus appear as an appropriate tool to rationalize the behaviour of catalytic reforming catalysts at the molecular scale. The guideline for future research in this area is the consideration of elements (such as $\mathrm{Sn}, \mathrm{Re}$, In, etc.) and their oxidation states accounting for the highly complex composition of the catalyst. Hopefully this approach will help to furnish rational guides to further improve the performances of the reforming catalyst.

\section{DEVELOPMENT OF COMPLETE PILOTS PANEL FOR CATALYST TESTING}

The validation of new catalysts by pilot plant testing with real feeds in operating conditions representative of industrial operating conditions is the last step of the catalyst development. But using multi sized pilot tools allows the validation of catalysts at different stages of their development:

- fast identification of promising ways by using the High Throughout Experimentation (HTE);

- confirmation of promising ways and refining catalyst formulations thanks to the micro pilot plant;

- understanding of the reaction mechanisms and the effect of promoters with specific molecular model tests;

- final validation of new catalyst formulation thanks to a pilot plant test functioning with real feeds in operating conditions representative of industrial operating conditions.

The development and setting up of these tools require full know-how that requires for example understanding and control of mass and heat transfer, analytical tools specifically developed to control real-time reactions and performance catalysts.

These pilot plant tests provide information such as activity, selectivity and stability of reforming catalysts.

\subsection{High Throughput Experimentation}

To improve the reforming catalysts, it is necessary today to introduce several promoters in addition to platinum to increase the activity, selectivity and stability. The study of introduction of news promoters involves the validation of the effects of these promoters using tests on the pilot plant. For that the use of a high throughput tool for validating the effect of new promoters and their crossed effects became inevitable. To this end, a pilot plant with sixteen reactors and 

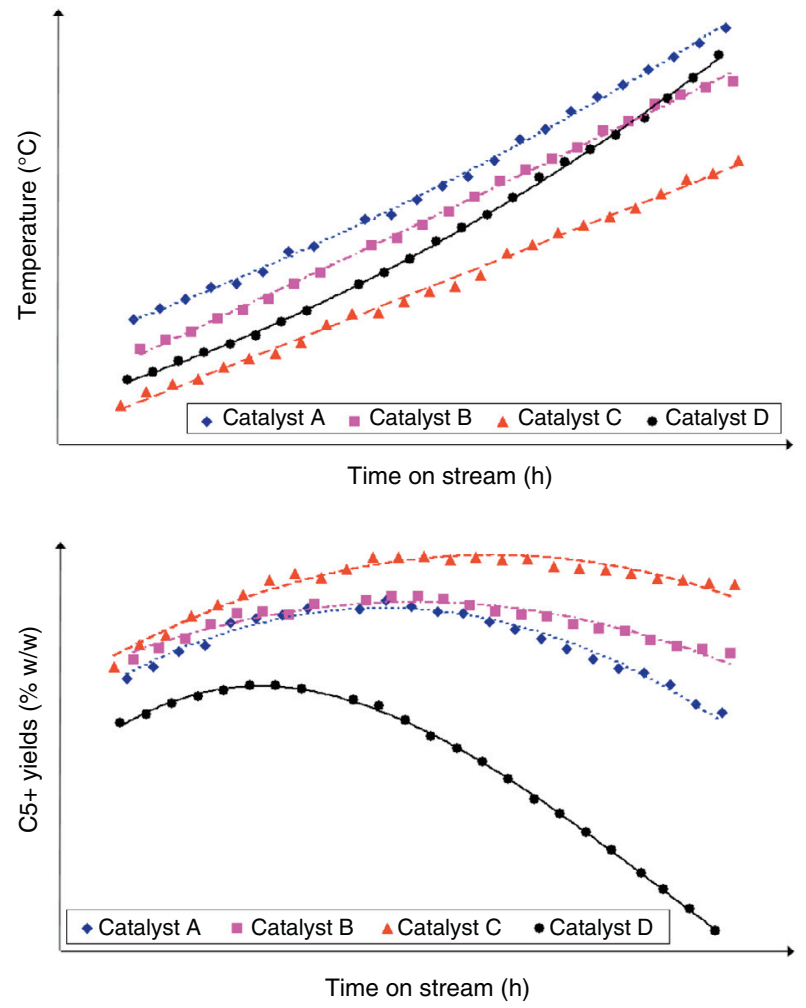

Figure 23

Temperature and selectivity as function of time on stream for four catalysts tested on micropilot for iso-RON mode.

a suitable test protocol has been developed to treat at IFPEN a high throughput of catalysts. This pilot plant allows to test a few hundred milligrams of catalysts prepared at a laboratory scale. The catalysts are loaded in tubular reactors with an appropriate loading allowing an isothermal temperature in the catalyst bed. The reactors are gathered in groups of four reactors operating at the same temperature and isothermal mode. A common control valve is used to regulate the pressure of the sixteen reactors. The feed and hydrogen rates are independent. A sequence of appropriate operating conditions can quickly select catalysts and compare the activities and selectivities of catalysts tested in a reasonable time test of a few days. Methods of testing and comparing the performance of catalysts have been developed to IFPEN and rely on a large database of tests.

\subsection{Micro Pilot Plants}

These assessment tool catalysts have four tubular reactors in parallel. Reactors allow the evaluation of a few grams of catalyst (typically 2 to $5 \mathrm{~g}$ ) in a catalyst bed having a temperature profile closer to the isothermal. Regulation of the flows of feed and hydrogen are independent for each reactor while the control valve is common for the four rectors.

An online system by Gas Chromatography (GC) analyzes the effluents of each reactor in turn. Software developed by IFPEN calculates the Research Octane Number (RON) from detailed analysis by GC. The RON of the produced reformate by each reactor is calculated in real time and therefore it is possible to adjust the temperature of each reactor to maintain a constant RON: these tests are conducted in iso-RON mode. This test mode allows to easily compare the activities, selectivities and stabilities of the catalysts for the same RON as shown in Figure 23. Of course, it is possible to know other information on the products formed in the reformate over time and to know the distribution between Fuel Gas (FG) and Liquefied Petroleum Gas (LPG) for example, or the evolution of different aromatic compounds over time.

These micro pilot plants allow, for example, to confirm the relevance of catalyst formulations identified using HTE but also to optimize the formulation of interesting catalysts with a pilot plant operating in iso-RON mode that is representative of a cycle of operation of industrial catalysts. These tools have recently been used for the development of a new multimetallic catalyst for Continuous Catalytic Reforing (CCR) [47].

\subsection{Molecular Model Tests}

Tests using a molecular model [48] is helpful for the understanding of the reaction mechanisms of reforming catalysts and the effects of the promoters studied. These short tests are performed at the laboratory scale on relatively simple pilot plants with small amounts of catalysts (a few grams).

The pilot plants consist of a mono reactor coupled to an online GC allowing the calculation of the conversion and the analysis of selectivities. This type of test is used to study the metal and acid functions of catalysts with relatively short time test procedures to compare the reactivity of the catalysts at different rates of coke. For example, using the dehydrogenation reaction of methyl cyclohexane to toluene [49] (Fig. 24), it is possible to study the metal function of catalysts, but also to obtain information about the secondary reactions such as isomerization to dimethylcyclopentane (combination of metal and acid functions) or dismutation to xylene and cyclohexane (acid function). Another interesting reaction to be studied is the reforming of $n$-heptane [50] as it is representative of all the reactions encountered in naphtha reforming but with a number of products formed significantly lower.

\subsection{Pilot Plant}

These tools provide the final validation of new processes and catalysts. This is a pilot plant for loading of a hundred grams 


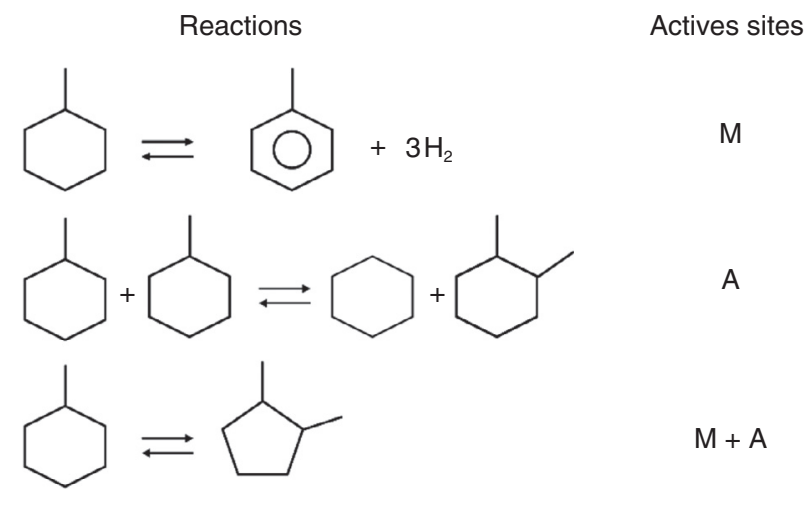

Figure 24

Methylcyclohexane dehydrogenation reaction and secondary reactions on reforming catalysts.

of catalyst in a tubular reactor whose temperature is controlled by a multipoint thermometer stick placed in the center reactor. The reactor is divided into seven zones whose filling is optimized to have perfect control of mass and heat transfer. The reactor operates isothermally with fluid circulation in downflow. A part of the effluent gas leaving the high pressure separator is recycled to the reactor inlet with flow regulated to obtain the desired ratio $\mathrm{H}_{2} / \mathrm{HC}$. The liquid effluent from the separator is fed to a stabilization column which the $\mathrm{C} 3 / \mathrm{C} 4$ ratio in the reformate is kept constant. An addition of chlorine to the feed is performed continuously according to the moisture content of the recycle gas which is controlled and regulated. The RON of reformate is kept constant by a continuous temperature gradient of the catalyst bed. Everyday materials balances are used to check the maintenance of the RON and adjust if necessary the temperature gradient. These pilot plants are essential to approach the industrial operating conditions such as recycle gas, the continuous chlorination of the catalyst, the humidity control, operation iso-RON.

\subsection{Conclusion}

To develop new reforming processes and catalysts, it is necessary to have varied and complementary tools test. Thus, the pilot plant developed allows large capacity to test new catalyst formulations, but also to better understand the effects of different promoters introduced in catalysts and validate processes and catalysts on a pilot plant operating close to the industrial operating conditions.

\section{CONCLUSION}

With a complete R\&D approach using new concepts and forefront methodology, IFPEN is able to:
- propose a patented reactor concept increasing capacity,

- ensure efficiency and safety of mechanical design for reactor,

- develop new catalysts to increase process performance due to a high comprehension of catalytic mechanism,

- have efficient and adapted pilots to validate catalyst performance.

To conclude, we could see that even for an old process like catalytic reforming, many improvements are possible particularly to obtain performance increase, economic gain and better security.

\section{REFERENCES}

1 Ginestra J.C., Jackson R. (1985) Pinning of a bed of particles in a vertical channel by a cross flow of gas, Industrial \& Engineering Chemistry Fundamentals 24, 2, 121-128.

3 Pilcher K.A., Bridgwater J. (1990) Pinning in a rectangular moving bed reactor with gas cross-flow, Chemical Engineering Science 45, 8, 2535-2542.

3 Pradel F., Lanaud C., Meimon Y. (2001) Interaction between granular and gas flows: the pinning effect, Powders and Grains 585-588.

4 Chen Y.H., Zhu X.D., Wul Y.Q., Zhu Z.B. (2007) Investigation of the effect of a dividing wall in a moving bed, Chemical Engineering \& Technology 30, 8, 1028-1035.

5 Sanchez E., Fershneider G., Bazer-Bachi F. (2011) Device for distributing feed and recovering effluents in a radial bed catalytic reactor, US 2011/0049013.

6 Snider D.M. (2001) An incompressible three-dimensional multiphase particle in cell model for dense particle flow, Journal of Computational Physics 170, 523-549.

7 Snider D.M. (2007) Three fundamental granular flow experiments and CPFD predictions, Powder Tech. 176, 36-46.

8 Lanaud C. (1996) Rhéologie des lits de catalyseurs, Application aux lits mobiles, Thesis, Université Lille 1.

9 Rahmoun J. (2007) Calcul des contraintes dans un matériau granulaire ensilé : comparaison entre les approches discrètes et continues, in $18^{e}$ Congrès français de mécanique, Grenoble, France, 27-31 août.

10 Bertho Y. (2003) Dynamiques d'écoulements gaz-particules en conduite verticale, Thesis, École Polytechnique.

11 Pradel F., Meimon Y. (2001) New Concept of Scallop Screens for Reactors of Refining, Oil \& Gas Science and Technology 56, 6, 597-610.

12 Paschero M., Hyer M.W. (2009) Axial buckling of an orthotropic circular cylinder: Application to orthogrid concept, International Journal of Solids and Structures 46, 2151-2171.

13 Sanchez E., Fershneider G., Bazer-Bachi F. (2009) Dispositif de rigidification des unités de conversion catalytique à lit radial, FR 2948580.

14 Vasiliev V.V. (1993) Mechanics of composites structures, Taylor and Francis.

15 Antos G.J., Aitani A.M. (2004) Preparation of Reforming catalysts, in Catalytic Naphtha Reforming, Antos, G.J., Aitani, A.M. (eds), Marcel Dekker, New York. 
16 Berry F.J., Jobson S., Zhang T., Marco J.F. (1991) In situ Characterization of Heterogeneous Catalysts by MossbauerSpectroscopy, Catalysis Today 9, 1-2, 137-143.

17 Jahel A., Avenier P., Lacombe S., Olivier-Fourcade J., Jumas J.-C. (2010) Effect of indium in trimetallic $\mathrm{Pt} / \mathrm{Al}_{2} \mathrm{O}_{3} \mathrm{SnIn}-\mathrm{Cl}$ naphtha-reforming catalysts, Journal of Catalysis 272, 2, 275-286.

18 Womes M., Le Peltier F., Morin S., Didillon B., OlivierFourcade J., Jumas J.-C. (2007) Study of the reaction mechanisms between $\mathrm{Sn}-\left(\mathrm{n}-\mathrm{C}_{4} \mathrm{H}_{9}\right)_{4}$ and alumina surface sites: Application to the controlled preparation of $\mathrm{PtSn} / \mathrm{Al}_{2} \mathrm{O}_{3}$ catalysts, Journal of Molecular Catalysis A: Chemical 266, 1-2, 55-64.

19 Jahel A., Avenier P., Lacombe S., Olivier-Fourcade J., Jumas J.-C. (2010) Investigation by Mossbauer spectroscopy of Sn redox transformations during $\mathrm{H}_{2} / \mathrm{O}_{2}$ titration on $\mathrm{Pt} / \mathrm{Al}_{2} \mathrm{O}_{3} \mathrm{Sn}-\mathrm{Cl}$ and $\mathrm{Pt} / \mathrm{Al}_{2} \mathrm{O}_{3} \mathrm{SnIn}-\mathrm{Cl}$ naphtha reforming catalysts, Journal of Physics: Conference Series 217, 012045-012048.

20 Jahel A., Lacombe S., Avenier P., Olivier-Fourcade J., Jumas J.-C. (2012) Mössbauer spectroscopy: an elegant tool for the active sites identification and quantification in Pt-Sn-In based naphtha reforming catalysts, Hyperfine Interaction 207, 1-3, 37-40.

21 Olivier-Fourcade J., Womes M., Jumas J.-C., Le Peltier F., Morin S., Didillon B. (2004) Investigation of redox properties of different $\mathrm{PtSn} / \mathrm{Al}_{2} \mathrm{O}_{3}$ catalysts, ChemPhysChem 5, 11, 1734-1744.

22 Singh J., Nelson R.C., Vicente B.C., Scott S.L., van Bokhoven J.A. (2010) Electronic structure of alumina-supported monometallic Pt and bimetallic PtSn catalysts under hydrogen and carbon monoxide environment, Physical Chemistry Chemical Physics 12, 21, 5668-5677.

23 Jahel A.N., Moizan-Basle V., Chizallet C., Raybaud P., OlivierFourcade J., Jumas J.-C., Avenier P., Lacombe S. (2012) Effect of Indium Doping of gamma-Alumina on the Stabilization of PtSn Alloyed Clusters Prepared by Surface Organostannic Chemistry, Journal of Physical Chemistry C 116, 18, 10073-10083.

$24 \mathrm{Hu}$ C.H., Chizallet C., Mager-Maury C., Corral-Valero M., Sautet P., Toulhoat H., Raybaud P. (2010) Modulation of catalyst particle structure upon support hydroxylation: $A b$ initio insights into $\mathrm{Pd}_{13}$ and $\mathrm{Pt}_{13} /$ gamma- $\mathrm{Al}_{2} \mathrm{O}_{3}$, Journal of Catalysis 274, 1, 99-110.

25 Mager-Maury C., Chizallet C., Sautet P., Raybaud P. (2012) Platinum Nanoclusters Stabilized on gamma-Alumina by Chlorine Used As a Capping Surface Ligand: A Density Functional Theory Study, ACS Catalysis 2, 7, 1346-1357.

26 Digne M., Sautet P., Raybaud P., Euzen P., Toulhoat H. (2002) Hydroxyl groups on gamma-alumina surfaces: A DFT study, Journal of Catalysis 211, 1, 1-5.

27 Digne M., Sautet P., Raybaud P., Euzen P., Toulhoat H. (2004) Use of DFT to achieve a rational understanding of acid-basic properties of gamma-alumina surfaces, Journal of Catalysis 226, 1, 54-68.

28 Digne M., Raybaud P., Sautet P., Guillaume D., Toulhoat H. (2008) Atomic scale insights on chlorinated gamma-alumina surfaces, Journal of the American Chemical Society 130, 33, 11030-11039.

29 Krokidis X., Raybaud P., Gobichon A.E., Rebours B., Euzen P., Toulhoat H. (2001) Theoretical study of the dehydration process of boehmite to gamma-alumina, Journal of Physical Chemistry $B$ 105, 22, 5121-5130.

$30 \mathrm{Hu}$ C.H., Chizallet C., Toulhoat H., Raybaud P. (2009) Structural, energetic, and electronic trends in low-dimensional latetransition-metal systems, Physical Review B 79, 195416.
31 Berdala J., Freund E., Lynch J.P. (1986) Environment of Platinum Atoms in a $\mathrm{H}_{2} \mathrm{PtCl}_{6} / \mathrm{Al}_{2} \mathrm{O}_{3}$ Catalyst - Influence of Metal Loading and Chlorine Content, Journal de Physique 47, C-8, 269-272.

32 Lynch J. (2002) Development of structural characterisation tools for catalysts, Oil \& Gas Science and Technology - Revue d'IFP Energies Nouvelles 57, 3, 281-305.

33 Mager-Maury C., Bonnard G., Chizallet C., Sautet P., Raybaud P. (2011) $\mathrm{H}_{2}$-Induced Reconstruction of Supported Pt Clusters: Metal-Support Interaction versus Surface Hydride, ChemCatChem 3, 1, 200-207.

34 Ji Y.Y., van der Eerden A.M.J., Koot V., Kooyman P.J., Meeldijk J.D., Weckhuysen B.M., Koningsberger D.C. (2005) Influence of support ionicity on the hydrogen chemisorption of Pt particles dispersed in $\mathrm{Y}$ zeolite: consequences for Pt particle size determination using the H/M method, Journal of Catalysis 234, 2, 376-384.

35 Kip B.J., Duivenvoorden F.B.M., Koningsberger D.C., Prins R. (1987) Determination of Metal-Particle Size of Highly Dispersed Rh, Ir, and Pt Catalysts by Hydrogen Chemisorption and EXAFS, Journal of Catalysis 105, 1, 26-38.

36 Bus E., Miller J.T., Kropf A.J., Prins R., van Bokhoven J.A. (2006) Analysis of in situ EXAFS data of supported metal catalysts using the third and fourth cumulant, Physical Chemistry Chemical Physics 8, 27, 3248-3258.

37 Ferreira-Aparicio P., Guerrero-Ruiz A., Rodriguez-Ramos I. (1997) Hydrogen adsorbed species at the metal/support interface on a Pt/ $\mathrm{Al}_{2} \mathrm{O}_{3}$ catalyst, Journal of the Chemical Society, Faraday Transactions 93, 19, 3563-3567.

38 Miller J.T., Meyers B.L., Modica F.S., Lane G.S., Vaarkamp M., Koningsberger D.C. (1993) Hydrogen TemperatureProgrammed Desorption ( $\left.\mathrm{H}_{2} \mathrm{TPD}\right)$ of Supported Platinum Catalysts, Journal of Catalysis 143, 2, 395-408.

39 Raybaud P., Chizallet C., Toulhoat H., Sautet P. (2012) Comment on "Electronic properties and charge transfer phenomena in Pt nanoparticles on gamma- $\mathrm{Al}_{2} \mathrm{O}_{3}$ : size, shape, support, and adsorbate effects" by F. Behafarid et al., Phys. Chem. Chem. Phys., 2012, 14, 11766-11779, Physical Chemistry Chemical Physics 14, 48, 16773-16774.

40 Sanchez S.I., Menard L.D., Bram A., Kang J.H., Small M.W., Nuzzo R.G., Frenkel A.I. (2009) The Emergence of Nonbulk Properties in Supported Metal Clusters: Negative Thermal Expansion and Atomic Disorder in Pt Nanoclusters Supported on Gamma- $\mathrm{Al}_{2} \mathrm{O}_{3}$, Journal of the American Chemical Society 131, 20, 7040-7054.

41 Gorczyca A., Moizan V., Chizallet C., Proux O., Del Net W., Lahera E., Hazemann J.L., Raybaud P., Joly Y. (2014) Monitoring Morphology and Hydrogen Coverage of Nanometric $\mathrm{Pt} / \gamma-\mathrm{Al}_{2} \mathrm{O}_{3}$ Particles by In Situ HERFD-XANES and Quantum Simulations, Angewandte Chemie, International Edition 46, 53, 12426-12429.

42 Raybaud P., Chizallet C., Mager-Maury C., Digne M., Toulhoat H., Sautet P. (2013) From gamma-alumina to supported platinum nanoclusters in reforming conditions: 10 years of DFT modeling and beyond, Journal of Catalysis 308, 1, 328-340.

43 Abolhamd G. (1980) Étude de l'influence de la modification de la fonction métallique sur l'activité deshydrocyclisante d'un catalyseur de reformage platine sur alumine, Thesis, Université Paris VI.

44 Bond G.C., Cunningham R.H. (1997) Alkane transformations on supported platinum catalysts. 4. Kinetics of hydrogenolysis of ethane, propane, and $n$-butane on $\mathrm{Pt} / \mathrm{Al}_{2} \mathrm{O}_{3}$ (EUROPT- 3 ) and $\mathrm{PtRe} / \mathrm{Al}_{2} \mathrm{O}_{3}$ (EUROPT-4), Journal of Catalysis 166, 2, 172-185. 
45 Bond G.C. (1999) Kinetics of alkane reactions on metal catalysts: activation energies and the compensation effect, Catalysis Today 49, 1-3, 41-48.

46 Franck J.P. (1984) Fundamental and industrial aspects of catalysis by metals, Imelik B., Martin G.A., Renouprez A.J. (eds), Édition du CNRS, Paris.

47 Le-Goff P.-Y., Lopez J., Ross J. (2012) Redefining reforming catalyst performance: High selectivity and stability, Hydrocarbon processing 47-52

48 Beltramini J.N., Martinelli E.E., Churin E.J., Figoli N.S., Parera J.M. (1983) $\mathrm{Pt} / \mathrm{Al}_{2} \mathrm{O}_{3}-\mathrm{Cl}$ in pure hydrocarbon reforming, Applied catalysis 7, 43-55.
49 Alhumaidan F., Cresswell D., Garforth A. (2010) Long-Term Deactivation of Supported Pt catalysts in the Dehydrogenation of Methylcyclohexane to Toluene, Industrial \& Engineering Chemistry Research 49, 9764-9770.

50 Mazzieri V.A., Grau J.M., Vera C.R., Yori J.C., Parera J.M., Pieck C.L. (2005) Pt-Re-Sn/ $/ \mathrm{Al}_{2} \mathrm{O}_{3}$ trimetallic catalysts for naphtha reforming processes without presulfiding step, Applied Catalysis A: General 296, 216-221.

Manuscript submitted in January 2015

Manuscript accepted in October 2015

Published online in May 2016

Cite this article as: P. Avenier, D. Bazer-Bachi, F. Bazer-Bachi, C. Chizallet, F. Deleau, F. Diehl, J. Gornay, É. Lemaire, V. Moizan-Basle, C. Plais, P. Raybaud, F. Richard and S. Lacombe (2016). Catalytic Reforming: Methodology and Process Development for a Constant Optimisation and Performance Enhancement, Oil Gas Sci. Technol 71, 41. 